\title{
Treatment of patients with heart failure and type 2 diabetes: a review of the literature
}

\author{
Elisa Fabbri, ${ }^{1}$ Maurizio Nizzoli ${ }^{1,2}$ \\ ${ }^{1}$ Internal Medicine Unit; and ${ }^{2}$ Endocrinology Unit, Morgagni-Pierantoni Hospital, Forlì (FC), Italy
}

\begin{abstract}
Heart failure (HF) and type 2 diabetes (T2D) often coexist and having both diseases compared with having only one is associated with greater challenges in their management/treatment and worse outcomes. The present review of the literature is aimed at providing a comprehensive synopsis of the main pieces of evidence of the treatment of the two coexisting conditions. In particular, the recent introduction of new glucose-lowering drugs has been deeply changing the therapeutic approach to T2D. Big randomized controlled trials (RCTs) developed to test the cardiovascular safety of these new drugs consistently highlighted a reduction in the risk of hospitalization for HF in patients with T2D treated with sodium-glucose co-transporter 2 (SGLT2) inhibitors, suggesting a potential and revolutionary class effect probably related to their natriuretic effect. Moreover, a renal protective effect of this drug class is also emerging and the beneficial effect of SGLT2 inhibitors on the risk of HF hospitalization seems to be even greater in patients with worse renal function. In conclusion, although the underlying mechanisms are not fully understood, SGLT2 inhibitors appear to be a promising tool to treat HF and T2D. Ongoing RCTs specifically enrolling patients with HF treated with SGLT2 inhibitors will provide more insights and further information.
\end{abstract}

\section{Introduction}

\section{Definitions and classifications}

Heart failure (HF) is a clinical syndrome characterized by typical symptoms (e.g., breathlessness, ankle swelling and fatigue) that may be accompanied by signs (e.g., elevated jugular venous pressure, pulmonary crackles and peripheral edema) caused by a structural and/or functional cardiac abnormality, resulting in a reduced cardiac output and/ or elevated intracardiac pressures at rest or under stress. ${ }^{1}$

Based on the measurement of left ventricular ejec-

Correspondence: Elisa Fabbri, Internal Medicine Unit, Morgagni-Pierantoni Hospital, Via Carlo Forlanini 34, 47121, Forlì (FC), Italy.

E-mail: elisa.fabbri4@auslromagna.it

Key words: Heart failure; type 2 diabetes; therapy; SGLT2 inhibitors.

Conflict of interests: the authors declare no potential conflict of interests.

Received for publication: 19 May 2019.

Revision received: 29 July 2019.

Accepted for publication: 19 August 2019.

This work is licensed under a Creative Commons Attribution NonCommercial 4.0 License (CC BY-NC 4.0).

${ }^{\circ}$ Copyright: the Author(s), 2019

Licensee PAGEPress, Italy

Italian Journal of Medicine 2019; 13:205-224

doi:10.4081/itjm.2019.1184 tion fraction (LVEF), HF is currently classified as heart failure with reduced ejection fraction ( $\mathrm{HFrEF}$ ) when LVEF $<40 \%$, and heart failure with preserved ejection fraction ( $\mathrm{HFpEF}$ ) when $\mathrm{LVEF} \geq 50 \%$. This distinction has practical implications since HFrEF and HFpEF present differences in epidemiology/etiology and they require different therapeutic approaches. In particular, the diagnosis of HFpEF is more challenging than the one of HFrEF. In fact, patients with HFpEF compared to those with HFrEF are usually older, more likely women, with a greater body mass index, a greater number of comorbidities, and a greater likelihood of having arterial hypertension or atrial fibrillation rather than a coronary disease. Moreover, while angiotensin-converting enzyme inhibitors (ACEIs), angiotensin receptor blockers (ARBs), $\beta$-blockers and mineralocorticoid receptor antagonists (MRAs) improve survival and are recommended in patients with HFrEF, they have all failed to reduce mortality in patients with HFpEF. Consequently, guidelines recommend in patients with HFpEF diuretic therapy to improve congestive symptoms and optimization of comorbidities management. However, HFpEF is still associated with elevated mortality. Of note, 2016 European Society of Cardiology (ESC) guidelines identify a third group including patients with an LVEF in the range of $40-49 \%$, referred as heart failure with mid-range ejection fraction (HFmrEF). This group actually represents a grey area, whose meaning is not yet fully understood; further studies are required. So far, patients with HFmrEF have generally been included in trials of HFpEF and guidelines recommend approaching them similarly to HFpEF. ${ }^{1}$ 
According to the World Health Organization, diabetes mellitus is a chronic disease caused by inherited and/or acquired deficiency in production of insulin by the pancreas, or by the ineffectiveness of the insulin produced, resulting in increased concentrations of glucose in the blood. There are two main types of diabetes: type 1 diabetes, due to autoimmune $\beta$-cell destruction leading to absolute insulin deficiency, whose onset is usually $<30$ years of age, and type $2 \mathrm{di}$ abetes (T2D), due to a progressive loss of $\beta$-cell insulin secretion frequently on the background of insulin resistance and metabolic syndrome, whose onset is usually $>40$ of age. ${ }^{2,3}$

For the purpose of this review, we will refer only to T2D.

\section{Epidemiology and prognosis}

HF and T2D often coexist ${ }^{4}$ and the presence of both diseases is associated with worse outcomes than having only one disease. ${ }^{5}$

Increasing age is a major risk factor for both HF and T2D. Thus, due to the population ageing, the prevalence of patients with both diseases is considerably rising, triggering complex challenges in their management. In particular, the prevalence of HF is about $12 \%$ in patients with $\mathrm{T} 2 \mathrm{D},{ }^{6}$ while the prevalence of T2D is $35-40 \%$ in patients with $\mathrm{HF}^{7}$

Noteworthy, the presence of T2D is associated with increased all-cause and cardiovascular mortality both in HFpEF and in HFrEF. Furthermore, patients with $\mathrm{HF}$ and T2D have a worse clinical status and New York Heart Association (NYHA) functional class, poorer quality of life, and higher risk of hospitalization for HF, longer hospital length and greater risk of re-hospitalization after discharge. ${ }^{4,8}$

Specifically, the relationship between the two diseases is likely to be bidirectional, with each one independently increasing the risk of the other. ${ }^{8}$

\section{Physiopathology}

The two main pathological conditions causally linking HF and T2D are coronary artery disease (CAD) and hypertension. ${ }^{4}$ However, a sizeable proportion of HF in patients with T2D develops in the absence of CAD and these patients are at high risk of mortality compared to those with a history of CAD. ${ }^{5}$

The term diabetic cardiomyopathy refers to a specific heart muscle disease, which occurs in diabetic patients in the absence of other cardiac risk factors such as CAD and hypertension. Specifically, insulin resistance and consequent hyperinsulinemia and hyperglycemia lead to specific changes in myocardial structure, metabolism and function which result in cardiac remodeling, fibrotic diastolic dysfunction and, ultimately, decreased ejection fraction. ${ }^{89}$ The main biological mechanisms un- derlying the development of diabetic cardiomyopathy include glucotoxicity, increased in advanced glycation end products, lipotoxicity, mitochondrial dysfunction and oxidative stress, impaired cardiomyopathy autophagy, inappropriate renin-angiotensin-aldosterone activation, maladaptive immune response and endothelial dysfunction, as extensively explained in previous specific reports on this topic. . $^{810}$

Left ventricular diastolic dysfunction and HFpEF occurred in about $75 \%$ and $50 \%$ of patients respectively with T2D, especially in older, hypertensive and female ones. On the other hand, the major cause of HFrEF in patients with T2D is CAD, which is usually diffuse, multivessel and may lead to silent myocardial infarction. ${ }^{4}$

\section{Treatment of heart failure in patients with type 2 diabetes}

Treatment of HF in patients with T2D is similar to treatment of HF in general, as recommended by 2016 ESC guidelines. ${ }^{1}$ Specifically, none of the drugs routinely used in the therapy of HF is contraindicated in the diabetic population.

As previously anticipated, the therapeutic approach should be based on the distinction between HFrEF and HFpEF/HFmrEF.

For the treatment of HFrEF, ACEis (or alternatively ARBs) plus $\beta$-blockers are recommended as first line therapy, with titration to the maximum tolerated dose. If patients are still symptomatic and have $\mathrm{LVEF} \leq 35 \%$, MRAs should be added. If still symptomatic, several options are possible. In patients who tolerate ACEis (or ARBs) in doses equivalent to enalapril $10 \mathrm{mg}$ b.i.d., angiotensin receptor neprilysin inhibitor, specifically LCZ696, which is a molecule that combines valsartan and sacubitril (a neprilysin inhibitor), should be used in place of ACEis (or ARBs). Alternatively, in patients with sinus rhythm and QRS $\geq 130$ milliseconds, cardiac resynchronization therapy should be evaluated. Finally, in patients with sinus rhythm and heart rate $\geq 70 \mathrm{bpm}$ ivabradine should be considered.

In patients with $\mathrm{HFpEF} / \mathrm{HFmrEF}$ trials of ACEis, ARBs, $\beta$-blockers and MRAs have all failed to reduce mortality. Therefore, 2016 ESC guidelines recommend to screen for and treat both cardiovascular $(\mathrm{CV}$ and non-CV comorbidities, including T2D, to improve symptoms, well-being and/or prognosis).

Of note, in both HFrEF and HFpEF/HFmrEF diuretics are recommended as symptomatic therapy to alleviate congestive symptoms and signs, without any effect on survival.

\section{Angiotensin-converting enzyme inhibitors}

Data from the studies of left ventricular dysfunction (SOLVD Investigators) showed that enalapril signifi- 
cantly reduced the occurrence of HF development and hospitalization, and the combined endpoint of HF development and $\mathrm{CV}$ death in asymptomatic patients with reduced LVEF $(\leq 35 \%)$ regardless of their diabetic status. ${ }^{11-13}$ Moreover, data from the Assessment of Treatment with Lisinopril And Survival (ATLAS) trial demonstrated the efficacy and the safety of high-dose lisinopril in patients with chronic $\mathrm{HF}$ at high $\mathrm{CV}$ risk, including those with diabetes mellitus. ${ }^{14} \mathrm{~A}$ meta-analysis of six randomized clinical trials confirms that ACEis reduce mortality in patients with $\mathrm{HFrEF}$ and T2D. ${ }^{15}$

Of note, enalapril was also found to reduce the incidence of T2D in patients with left ventricular dysfunction. ${ }^{16}$

\section{Angiotensin receptor blockers}

In the Valsartan Heart Failure Trial (Val-HeFT), valsartan $160 \mathrm{mg}$ compared to placebo was associated with a significant reduction in the combined primary endpoint of death and HF hospitalization in more than 5000 patients with HF of NYHA class II, III or IV, and with and without T2D. ${ }^{17,18}$ Moreover, in the Candesartan in Heart failure-Assessment of Reduction in Mortality and morbidity (CHARM) trial, enrolling about 7600 patients with HFrEF, Candesartan significantly reduced all-cause mortality, CV death and HF hospitalization, independent of their diabetic status. ${ }^{19-21}$

Furthermore, in the Heart failure Endpoint evaluation of Angiotensin II Antagonist Losartan (HEAAL) study, losartan was found to reduce HF hospitalization in patients with T2D and nephropathy. ${ }^{22}$ Specifically, higher dose of losartan (150 mg daily) significantly reduced death and HF hospitalization compared to lower dose (50 mg daily) in patients with $\mathrm{HFrEF}$ and intolerance to ACEi, irrespective of their diabetes status. ${ }^{23}$ In addition, data from Reduction of Endpoints in NIDDM with the Angiotensin II Antagonist Losar$\tan$ (RENAAL) and Losartan Intervention For Endpoint reduction in hypertension (LIFE) studies showed that losartan reduces the risk of HF hospitalization in patients with T2D at high renal or CV risk. ${ }^{24}$ Finally, candesartan was found to prevent diabetes in patients with $\mathrm{HF}^{25}$

\footnotetext{
Aliskiren

Aliskiren is a direct renin inhibitor that blocks the renin-angiotensin-aldosterone system at the most proximal step. The Aliskiren trial in Type 2 Diabetes Using cardio renal Endpoint (ALTITUTE) was designed to investigate the effect of aliskiren in T2D patients with proteinuria or $\mathrm{CV}$ disease but it was stopped early because of an increased risk of adverse effects including renal dysfunction and hyperkaliemia. ${ }^{26}$ The Aliskiren Trial on Acute Heart Failure Outcomes (ASTRONAUT) enrolled patients
}

with T2D hospitalized for HF but it showed an increased risk of 12 -month mortality probably mediated by the increased adverse effects. ${ }^{27}$ In the Aliskiren Trial of Minimizing OutcomeS for Patients with HEart failuRE (ATMOSPHERE), 7016 patients HFrEF were randomized to enalapril plus aliskiren, aliskiren alone, or enalapril. As it results, the addition of aliskiren to enalapril led to more adverse events without an increase in benefit. In addition, non-inferiority was not shown for aliskiren as compared with enalapril. ${ }^{28} \mathrm{~A}$ subsequent subgroup analysis in patients with and without T2D confirmed that there was no signal of harm and a trend towards benefit when direct renin inhibition monotherapy was compared with an angiotensin-converting enzyme inhibitor, whereas combined aliskiren and enalapril treatment led to more adverse events with no improvement in outcomes. ${ }^{29}$

\section{$\beta$-blockers}

In the Metoprolol CR/XL Randomized Intervention Trial in Chronic Heart Failure (MERIT-HF), metoprolol reduced the risk of hospitalization for HF by $37 \%$ in the diabetic group [ $95 \%$ confidence interval (CI) $53 \%-15 \%$ ], and by $35 \%$ in the non-diabetic group (95\% CI 48\%-19\%). ${ }^{30}$ Moreover, in the Cardiac Insufficiency Bisoprolol Study II (CIBIS II), bisoprolol demonstrated significant mortality benefits in patients with chronic HF irrespectively of their diabetic status. ${ }^{31,32}$ Furthermore, in the Carvedilol Prospective Randomized Cumulative Survival (COPERNICUS) study, patients with severe chronic HFrHF receiving carvedilol in addition to their usual medications for HF presented a significant reduction in death and hospitalization compared to those receiving placebo. ${ }^{33,34}$ Besides, concomitant diabetes was found not to influence the efficacy and tolerability of carvedilol administration in 193 patients with chronic HF. ${ }^{35}$ Additionally, in the Carvedilol Or Metoprolol European Trial (COMET), carvedilol extends survival as compared with metoprolol ${ }^{36}$ and new onset diabetes is more likely to occur during treatment with metoprolol than during treatment with carvedilol. ${ }^{37}$

A meta-analysis of six large randomized clinical trials found that $\beta$-blocker therapy as compared with placebo in chronic HF was beneficial in patients with or without T2D, but the absolute risk reduction in mortality was greater in those without T2D than in those with T2D. ${ }^{38} \mathrm{~A}$ further meta-analysis of three studies (CIBIS, COPERNICUS, MERIT-HF) found that the relative risk $(95 \% \mathrm{CI})$ of mortality was $0.65(0.57$ $0.74)$ in the non-diabetic group and 0.77 (0.61-0.96) in the diabetic group. ${ }^{15}$ An additional meta-analysis of seven large placebo-controlled randomized trials with carvedilol showed similar survival benefits in HF patients with and without T2D. ${ }^{39}$ Noteworthy, $\beta$-blockers use did not worsen glycemic control in patients with 
HFrEF and T2D. ${ }^{40}$ Finally, in a recent study increasing $\beta$-blocker dose was associated with a greater prognostic advantage in chronic HF patients with diabetes than in those without diabetes. ${ }^{41}$

\section{Mineralocorticoid receptor antagonists}

In the Randomized Aldactone Evaluation Study (RALES), spironolactone as compared with placebo significantly reduced death and HF hospitalization in patients with HFrEF.42 Subsequently, in the Eplerenone in Mild Patients Hospitalization and Survival Study in Heart Failure (EMPHASIS-HF) eplerenone compared to placebo was found to significantly reduce mortality and HF hospitalization in patients with HFrEF irrespective of their diabetic status. ${ }^{43}$ Moreover, eplerenone was found to have no effect on new-onset diabetes in patients with chronic HF. ${ }^{44}$ Furthermore, in the Miner Alocorticoid Receptor antagonist Tolerability Study-Heart Failure (ARTSHF), the effects of finerenone were compared to eplerenone in patients with worsening HFrEF and chronic kidney disease (CKD) or T2D presenting at the emergency department. ${ }^{45}$ As a result, finerenone safety profile was comparable to that of eplerenone. In addition, change in NT-proBNP from baseline to Day 90 was similar between finerenone and eplerenone. However, the incidence of the exploratory composite endpoint of death from any cause, cardiovascular hospitalization, or emergency presentation for worsening HF at Day 90 was lower in patients treated with finerenone compared with eplerenone. ${ }^{46}$

\section{Sacubitril/Valsartan (LCZ696)}

In the PARADIGM-HF trial, 8442 patients with HFrEF were randomized to receive either LCZ696 (at a dose of $200 \mathrm{mg}$ twice daily) or enalapril (at a dose of $10 \mathrm{mg}$ twice daily), in addition to recommended therapy. As a result, LCZ696 was superior to enalapril in reducing the risk of death from any cause $[17 \% \mathrm{vs}$ $19.8 \%$, hazard ratio (HR) $0.84,95 \% \mathrm{CI}, 0.76$ to 0.93 ; $\mathrm{P}<0.001]$ and $\mathrm{CV}$ death (13.3\% vs $16.5 \%$, HR 0.80 , $95 \%$ CI, 0.71 to $0.89 ; \mathrm{P}<0.001)$. Moreover, LCZ696 reduced the risk of hospitalization for HF by $21 \%$ $(\mathrm{P}<0.001) .{ }^{47}$ Furthermore, a subsequent subgroup analysis demonstrated that the beneficial effect of LCZ696 was irrespective of the diabetic status. ${ }^{48}$ Finally, a post hoc analysis showed that patients with T2D and HFrEF enrolled in PARADIGM-HF who received sacubitril/valsartan had a greater long-term reduction in $\mathrm{HbA}_{1 \mathrm{c}}$ and a lower rate of initiation of insulin than those receiving enalapril. ${ }^{49}$

Noteworthy, several mechanisms might underlie the hypoglycemic effect of sacubitril/valsartan.

First, in the Nateglinide and Valsartan in Impaired Glucose Tolerance Outcomes Research (NAVIGA-
TOR) study valsartan significantly reduced the incidence of T2D among patients with impaired glucose tolerance and established $\mathrm{CV}$ disease or $\mathrm{CV}$ risk factors. ${ }^{50}$ Consistently with these findings, a subsequent study showed that valsartan improves insulin sensitivity and $\beta$-cell function in subjects with impaired glucose metabolism. ${ }^{51}$

Moreover, sacubitril inhibits neprilysin, an enzyme that is responsible for the breakdown of a series of peptides, including glucagon-like peptide-1 (GLP-1), natriuretic peptides and bradykinins, resulting in increased levels of such peptides with consequent positive effects on glucose metabolism. ${ }^{49}$ In particular, GLP-1 is an incretin that stimulates the pancreatic secretion of insulin and inhibits the one of glucagon. Noteworthy, GLP-1 is degraded not only by dipeptidyl peptidase-4 (DPP4) but also by neprilysin. ${ }^{52}$ Therefore, neprilysin inhibition potentiates the effect of GLP-1 and decreases blood glucose. ${ }^{53}$ Consistently, experimental studies found that levels of GLP-1 are increased in neprilysin-deficient mice, leading to improved glycemic control. ${ }^{54}$ Natriuretic peptides, including atrial and brain natriuretic peptides (ANP and $\mathrm{BNP}$ respectively), are heart hormones produced by the right atrium in response to overload and mechanical stretch in order to regulate blood volume and pressure. Besides their well-known cardiovascular effects, several studies documented that natriuretic peptides have also an important role in the regulation of the energy metabolism. In particular, ANP was found to increase lipid mobilization from adipose tissue ${ }^{55}$ and postprandial lipid oxidation..$^{56}$ Moreover, natriuretic peptides enhance the oxidative capacity of human skeletal muscle ${ }^{57}$ and play an important role in maintaining long-term insulin sensitivity. ${ }^{58}$ Consistently, blood glucose concentrations have been found to decrease after infusion of BNP. ${ }^{59}$ Besides, in a prospective analysis including 7822 participants from the Atherosclerosis Risk in Communities (ARIC) study, baseline higher levels of NT-proBNP, a cleavage product of BNP, were significantly and independently associated with a decreased risk of incident diabetes. ${ }^{60}$ Finally, bradykinins, which are inflammatory mediators with vasoactive effects, also seem to be involved in the regulation of blood glucose levels by improving systemic insulin sensitivity. ${ }^{61}$

Noteworthy, the PARAGON-HF (ID: NCT01920711) is an ongoing trial aimed at evaluating the effect of LCZ696 compared to valsartan in the reduction of CV death and HF hospitalizations in 4822 patients with HFrEF, of which $43 \%$ have T2D. ${ }^{62}$

\section{Nitrates}

The African-American Heart Failure Trial (AHeFT) reported that the fixed-dose combination of isosorbide dinitrate and hydralazine hydrochloride sig- 
nificantly decreased the risk of all-cause death and first hospitalization for HF with a consistent beneficial effect in patients with and without T2D. ${ }^{63}$

\section{Ivabradine}

A post hoc analysis on patients enrolled in the Systolic Heart failure treatment with the $I_{\mathrm{f}}$ inhibitor ivabradine Trial (SHIFT) examined the efficacy and safety of ivabradine in patients with HFrEF and T2D. As a result, ivabradine significantly reduced the primary composite endpoint of CV death and HF hospitalization with no difference between patients with and without T2D. ${ }^{64}$

\section{Diuretics}

Diuretics are recommended to treat congestive symptoms. There are no trials examining their efficacy in persons with HF and T2D. Theoretically, thiazide diuretics can lead to increased insulin resistance and worsening of glycemic control. ${ }^{4}$

\section{Treatment of type 2 diabetes in patients with heart failure}

\section{Glycemic control and target}

Results from the UK Prospective Diabetes Study (UKPDS), ${ }^{65}$ the Action to Control Cardiovascular risk in Diabetes (ACCORD) ${ }^{66}$ study, the Action in Diabetes and Vascular Disease: Preterax and Diamicron Modified Release controlled Evaluation (ADVANCE) ${ }^{67}$ and the Veterans Affairs Diabetes trial $(\mathrm{VADT})^{68}$ agreed on the fact that intensive glycemic control in patients with T2D was associated with reduced incidence of microvascular complications (nephropathy, neuropathy and retinopathy). However, they did not consistently demonstrate benefits from intensive glycemic control on macrovascular risk, especially in the oldest and frail patients with longstanding T2D, multiple comorbidities, previous CV events or high CV risk and high risk of hypoglycemia. Therefore, whether an intensive glycemic control may affect the risk of CV events in patients with HF is uncertain. In particular, meta-analyses pooling data from the four studies together found that intensive glycemic control does not reduce cardiovascular mortality or HF hospitalization but it increases the risk of hypoglycemia. ${ }^{69,70}$ Therefore, guidelines recommend individualized and patient-centered $\mathrm{HbAlc}$ targets, that should be tighter in younger patients with recent onset T2D and without complications/comorbidities $(<6.5-$ $7 \% \mathrm{HbA} 1 \mathrm{c})$ and looser in older patients with longstanding T2D, short life expectancy, important comorbidities and/or established CV complications $(<8-9 \text { HbAlc) })^{3,71}$

\section{Pharmacological treatment}

Metformin, if not contraindicated and if tolerated, is the preferred initial pharmacological treatment in patients with T2D. In case of great metabolic imbalance, initiating with dual therapy is recommended. When monotherapy with metformin is not able to achieve an adequate glycemic control, a second oral glucose-lowering drug should be associated. When dual therapy is still not able to reach a satisfactory glycemic control, a third oral glucose-lowering drug should be added. If an insufficient glycemic control persists, a combination injectable therapy (adding insulin or GLP1-RA) should be considered. ${ }^{72}$

The choice of the drug/drugs to combine with metformin depends on the characteristics of the patients, including comorbidities. In congestive HF, metformin should be the first choice. Thiazolidinediones are contraindicated, while insulin/sulfonylureas/glinides should be used with caution. Regarding new oral antidiabetic drugs, safety data of DPP4 inhibitors and GLP1-RA in patients with HF are limited, while promising pieces of evidence are emerging for SGLT2 inhibitors, as detailed in the following paragraphs.

\section{Biguanides (metformin)}

Metformin therapy has long been avoided in patients with HF, because of the fear of lactic acidosis in unstable patients..$^{73}$ However, observational studies demonstrated that metformin reduces mortality in patients with HF. ${ }^{74-76}$ Therefore, the U.S. Food and Drug Administration (FDA) removed HF as a contraindication to metformin use in 2006, although acute or unstable HF remains a precaution. ${ }^{73}$ Moreover, 2016 ESC guidelines for the management of HF patients established that metformin is safe and should be considered as a first-line treatment of glycemic control in patients with T2D and HF, unless contraindicated. ${ }^{1}$ Of note, metformin is contraindicated in patients with severe renal impairment (estimated glomerular filtration rate, eGFR $<30 \mathrm{~mL} / \mathrm{min})$.

\section{Insulin}

Insulin is a powerful dose dependent sodium-retaining hormone, that when combined with reduced glycosuria may aggravate fluid retention and lead to HF worsening. Some observational studies found that insulin-treated T2D was associated with increased mortality in patients with HF. ${ }^{77-80}$ However, insulintreated patients are usually older, with long standing $\mathrm{T} 2 \mathrm{D}$, greater comorbidities and CV complications and this may represent a bias. ${ }^{81}$ Of note, the Outcome Reduction with Initial Glargine Intervention (ORIGIN) trial evaluated the effects of insulin glargine vs standard therapy in patients with impaired fasting glucose, or impaired glucose tolerance or T2D at high $\mathrm{CV}$ risk 
(but without prevalent HF that was an exclusion criterion). As a result, it found no significant differences in $\mathrm{CV}$ death, non-fatal myocardial infarction, non-fatal stroke, CV revascularization procedures or HF hospitalization. ${ }^{82}$ Moreover, one small, randomized clinical trial investigated the effect of insulin on cardiac function in 40 patients with T2D and HFrEF, finding no changes in left ventricular reserve capacity. ${ }^{83}$ In conclusion, insulin should be used with caution in HF patients and monitoring signs and symptoms of fluid retention.

\section{Sulfonylureas}

Sulfonylureas may cause hypoglycemia and weight gain and previous evidence showed that they have been associated with an increased risk of worsening HF.

For instance, a retrospective cohort study of T2D patients without HF newly treated with oral antidiabetic drugs found that incidence of HF was greater in those taking sulfonylureas than metformin and that higher doses of sulfonylureas were associated with higher risk. ${ }^{84}$ In the UK General Practice Research Database, monotherapy with first- or second-generation sulfonylureas was associated with an 18-30\% increased risk of HF as compared with metformin. ${ }^{85}$ Moreover, a recent real-world study using data from the National Veterans Health Administration database found that the prescription of sulfonylureas as initial treatment of T2D was associated with a $32 \%$ increase in the risk of $\mathrm{HF}$ as compared with metformin. ${ }^{86}$

Therefore, sulfonylureas should be used with caution in patients with HF. ${ }^{1}$

Regarding the pathophysiological mechanisms throught which sulfonylureas might worsen HF, a plausible explanation relates to hypoglycemia since it has been previously associated with an increased risk of severe ventricular arrhythmias, $\mathrm{CV}$ events and mortality. ${ }^{87-90}$ Moreover, sulfonylureas non-selective for pancreatic receptors, such as glibenclamide, inhibit the adenosine triphosphate sensitive potassium $\left(\mathrm{K}_{\mathrm{ATP}}\right)$ channels located on the inner membrane of mitochondria and on the sarcolemma of cardiac, skeletal and smooth muscle cells. $\mathrm{K}_{\mathrm{ATP}}$ channels are metabolic sensors that promote vasodilatation in response to specific signals, such as acidosis and hypoxia, ${ }^{91}$ and are important for myocardial protection during ischemia/reperfusion (i.e. ischemic preconditioning). Experimental studies showed that, in the failing heart, $\mathrm{K}_{\mathrm{ATP}}$ channels play a critical role in maintaining the balance between myocardial oxygen delivery and demand, and in mediating the response to stress. ${ }^{91}$ Therefore, glibenclamide, blocking cardiovascular $\mathrm{K}_{\mathrm{ATP}}$ channels, leads to vasoconstriction and decrease in coronary blood flow. Noteworthy, in animal models glibenclamide has been associated with reduced myocardial perfusion and development of tissue hypoxia in congestive HF. ${ }^{91}$ Moreover, in human patients with T2D and coronary artery disease, treatment with glibenclamide compared to insulin was associated with a more severe ischemiainduced left ventricular myocardial dysfunction due to the loss of the ischemic preconditioning cardioprotective mechanism..$^{92}$ Furthermore, a recent study showed that inhibition of vascular $\mathrm{K}_{\text {ATP }}$ channels by glibenclamide exacerbates skeletal muscle $\mathrm{O}_{2}$ delivery-utilization mismatch during contractions in rats with chronic HF, suggesting that the administration of non-selective sulfonylureas in patients T2D and congestive HF may severely compromise exercise tolerance. $^{93}$ Conversely, sulfonylureas selective for pancreatic receptors, such as gliclazide or glimepiride, seem to be safer as they cause fewer CV effects. In particular, lack of effect on ischemic preconditioning was found for glimepiride. ${ }^{94-96}$ Moreover, data from the ADVANCE study showed no difference in the incidence of HF in T2D patients treated with gliclazide compared to placebo. ${ }^{67}$

\section{Thiazolidinediones}

Thiazolidinediones (glitazones) cause sodium and water retention. Therefore, they increase the risk of HF worsening and hospitalization and are not recommended in patients with HF. ${ }^{97,98}$

\section{DPP4 inhibitors}

The protease dipeptidyl peptidase-4 (DPP-4) inhibitors are a new class of anti-diabetic drugs that inhibits the protease DPP-4, which is responsible for the degradation of incretins with consequent increase in their circulating levels. Incretins, including the glucagon-like peptide-1 (GLP-1) and the gastric inhibitory polypeptide, are gut hormones synthetized and secreted by enteric endocrine cells in response to food intake that increase glucose-dependent insulin secretion and decrease glucagon secretion with consequent reduction of blood glucose levels with low hypoglycemia risk.

Therefore, DPP-4 inhibitors, including saxagliptin, alogliptin, sitagliptin, vildagliptin and linagliptin, reduce blood glucose levels with low hypoglycemia risk and with no relevant effect on body weight.

\section{Saxagliptin}

The Saxagliptin Assessment of vascular outcomes Recorded in Patients with Diabetes Mellitus - Thrombolysis in myocardial infarction 53 (SAVOR-TIMI 53) trial assessed the efficacy and safety of saxagliptin in 16,492 patients with T2D and a history of or at risk of $\mathrm{CV}$ events, randomized to receive saxagliptin or placebo and followed for a median of 2.1 years. A primary composite endpoint event (including $\mathrm{CV}$ death, 
non-fatal myocardial infarction, or non-fatal ischemic stroke) occurred in 613 patients in the saxagliptin group and in 609 patients in the placebo group $(7.3 \%$ and $7.2 \%$, respectively; HR 1.00, 95\% CI $0.89-1.12$; $\mathrm{P}=0.99$ for superiority; $\mathrm{P}<0.001$ for non-inferiority). However, more patients in the saxagliptin group than in the placebo group were hospitalized for $\mathrm{HF}(3.5 \%$ vs $2.8 \%$; HR 1.27; 95\% CI 1.07-1.51; $\mathrm{P}=0.007) .{ }^{99} \mathrm{In}$ particular, the risk of HF hospitalization with saxagliptin was most evident in the first 12 months of therapy. Moreover, a subsequent analysis showed that this increase in risk was highest among patients with elevated levels of natriuretic peptides, previous HF, or CKD. ${ }^{100}$ Of note, the increased risk of HF hospitalization was irrespective of age category. ${ }^{101}$

\section{Alogliptin}

In the EXAMINE trial, 5380 patients with T2D and a recent acute coronary syndrome (ACS) event were randomized to receive alogliptin or placebo and followed for a median of 18 months. As a result, alogliptin was non-inferior to placebo in lowering the risk of the composite primary endpoint of $\mathrm{CV}$ death, myocardial infarction, or stroke $(11.3 \%$ vs $11.8 \%$, HR 0.96; upper boundary of the one-sided repeated CI 1.16; $\mathrm{P}<0.001$ for non-inferiority). ${ }^{102}$ Moreover, first hospital admission for HF occurred in $85(3.1 \%)$ patients taking alogliptin compared to $79(2.9 \%)$ taking placebo (HR 1.07, 95\% CI 0.79-1.46), showing a non-significant trend to an increase in HF hospitalization. ${ }^{103}$

\section{Sitagliptin}

In the Trial Evaluating Cardiovascular Outcomes with Sitagliptin (TECOS), 14,671 patients were randomized to add either sitagliptin or placebo to their existing therapy and followed for a median of 3 years. As a result, sitagliptin was non-inferior to placebo for the primary composite outcome of $\mathrm{CV}$ death, non-fatal myocardial infarction, non-fatal stroke, or hospitalization for unstable angina (HR 0.98; 95\% CI 0.88-1.09; $\mathrm{P}<0.001)$. Rates of hospitalization for HF did not differ between the two groups (HR 1.00; 95\%CI 0.831.20; $\mathrm{P}=0.98) .{ }^{104} \mathrm{~A}$ subsequent analysis from TECOS confirmed that sitagliptin does not affect the risk of HF hospitalization in T2DM, both overall and among high-risk patient subgroups. ${ }^{105}$

Consistently a meta-analysis of 10 studies including 340,747 patients demonstrated that sitagliptin exposure was not associated with the incidence of HF. ${ }^{106}$

Of note, a population-based retrospective cohort study using data from a national commercially insured U.S. claims database showed that sitagliptin was associated with an increased risk of HF hospitalization among patients with T2D with pre-existing HF. ${ }^{107}$

\section{Vildagliptin}

The Vildagliptin in Ventricular Dysfunction Diabetes (VIVIDD) trial enrolled 254 patients with T2D and HFrEF randomized to 52 weeks treatment with vildagliptin $50 \mathrm{mg}$ twice daily $(50 \mathrm{mg}$ once daily if treated with a sulfonylurea) vs placebo in addition to standard therapy. The primary endpoint was betweentreatment change from baseline in echocardiographic LVEF. As a result, compared with placebo, vildagliptin had no major effect on LVEF but did lead to an increase in left ventricular volumes, the cause and clinical significance of which is unknown. ${ }^{108}$

A meta-analysis did not find a significant increased risk of HF in vildagliptin-treated patients. ${ }^{109}$

\section{Linagliptin}

The Cardiovascular and Renal Microvascular Outcome Study with Linagliptin (CARMELINA) trial enrolled 6979 participants with T2D and atherosclerotic CV disease and/or kidney disease randomized to receive once daily oral linagliptin $5 \mathrm{mg}$ or placebo. During a median follow-up of 2.2 years, the primary outcome (i.e. time to first occurrence of the composite of $\mathrm{CV}$ death, nonfatal myocardial infarction, or nonfatal stroke) occurred in 434 of 3494 (12.4\%) and 420 of $3485(12.1 \%)$ in the linagliptin and placebo groups respectively (HR 1.02; 95\% CI, 0.89-1.17; $\mathrm{P}<0.001$ for non-inferiority). ${ }^{110}$ In addition, linagliptin versus placebo did not affect the incidence of HF hospitalization (HR $0.90 ; 95 \% \mathrm{CI} 0.74-1.08$ ), the composite of $\mathrm{CV}$ death/HF hospitalization (HR 0.94; 95\% CI, 0.821.08), or risk of recurrent HF hospitalization (HR 0.94; 95\% CI, 0.75-1.20). ${ }^{111}$

Finally, the Cardiovascular Outcome Study of Linagliptin Versus Glimepiride in Patients with Type 2 Diabetes (CAROLINA) is an ongoing study aimed at investigating the long-term impact of linagliptin, as compared with glimepiride, on CV morbidity and mortality, relevant efficacy parameters (e.g., glycemic parameters) and safety (e.g., weight and hypoglycemia) in patients with $\mathrm{T} 2 \mathrm{D}$ at elevated $\mathrm{CV}$ risk (ClinicalTrials.gov, ID: NCT01243424). ${ }^{112}$

\section{GLP-1 receptor agonists}

GLP-1 receptor agonists (GLP1-RA), including short acting (exenatide and lixisenatide) and long acting (liraglutide, semaglutide, extended-release exenatide and dulaglutide) agents, are a new class of antidiabetic drugs, that improves glycemic control with a low risk of hypoglycemia and the additional benefit of clinically relevant weight loss.

Data from experimental studies suggested a cardio protective effect of GLP1 RA ${ }^{113,114}$ and a small pilot study proposed that they might improve cardiac function in patients with advanced HF. ${ }^{115}$ However, 
some evidence from randomized and observational studies demonstrated only a modest effect on left ventricular EF. ${ }^{116}$

\section{Lixisenatide}

The Evaluation of Lixisenatide in Acute Coronary Syndrome (ELIXA) trial enrolled 6068 patients with T2D who recently had ACS randomized to receive lixisenatide or placebo in addition to locally determined standards of care. As a result, no significant difference was found in the occurrence of the primary composite endpoint of CV death, myocardial infarction, stroke, or hospitalization for unstable angina between lixisenatide and placebo (HR 1.02; 95\%CI $0.89-1.17$, $\mathrm{P}$ for non-inferiority $<0.001$ but $\mathrm{P}$ for superiority $=0.81$ ). Moreover, there was no significant between-group difference in the rate of hospitalization for HF (HR 0.96; 95\%CI 0.75-1.23). ${ }^{117}$

A further analysis showed that in patients with T2DM and recent ACS, a history of retinopathy and/or neuropathy and longer T2DM duration could be considered clinical markers for high risk of recurrent $\mathrm{CV}$ events. ${ }^{118}$

\section{Liraglutide}

The Liraglutide Effect and Action in Diabetes: Evaluation of cardiovascular outcome Results (LEADER) trial assessed the cardiovascular safety of liraglutide in 9340 patients with T2D, randomized to receive either $1.8 \mathrm{mg}$ (or the maximum tolerated dose) of liraglutide or matching placebo once daily as a subcutaneous injection in addition to standard care. ${ }^{119}$ As a result, the primary composite outcome, consisting of the first occurrence of $\mathrm{CV}$ death, nonfatal myocardial infarction, or nonfatal stroke, occurred in significantly fewer patients in the liraglutide group than in the placebo (HR 0.87; 95\%CI 0.78-0.97; $\mathrm{P}<0.001$ for noninferiority; $\mathrm{P}=0.01$ for superiority). In addition, fewer patients died from $\mathrm{CV}$ causes in the liraglutide group than in the placebo group (HR 0.78; 95\%CI 0.66-0.93; $\mathrm{P}=0.007$ ). Moreover, the rate of death from any cause was lower in the liraglutide group than in the placebo group (HR 0.85; 95\%CI 0.74-0.97; $\mathrm{P}=0.02$ ). However, no significant difference was found in the rate of hospitalization for HF between the two groups (HR 0.87, 95\%CI 0.73-1.05). ${ }^{120}$ Furthermore, a subsequent analysis from the LEADER showed that liraglutide resulted in lower rates of the development and progression of diabetic kidney disease than placebo. ${ }^{121}$

Besides, two further studies specifically investigated the effect of liraglutide in patients with T2D and HFrEF.

The FIGHT trial enrolled 300 patients with established HF and reduced LVEF who were recently hospitalized, randomized to liraglutide $1.8 \mathrm{mg}$ daily versus placebo and followed for a mean of 210 days. As a result, regardless of T2D status, liraglutide had no significant effect on the primary endpoint, a hierarchical global rank score including time to death, time to re-hospitalization for HF and time-averaged proportional change in NT-proBNP level from baseline to 180 days $(\mathrm{P}=0.31)$. In particular, no significant between-group difference was found in HF hospitalization (HR 1.30, 95\%CI 0.89-1.88; $\mathrm{P}=0.17$ ). ${ }^{122}$

The LIVE Study enrolled 241 patients with chronic HF and reduced LVEF $(\leq 45 \%)$ with and without T2D, randomized to liraglutide $1.8 \mathrm{mg}$ once daily VS placebo for 24 weeks. ${ }^{123}$ As a result, no significant difference in change in LVEF was found between the liraglutide and the placebo group $(\mathrm{P}=0.24)$. In addition, no significant change in LV dimensions, NYHA class or quality of life were reported. The results were consistent in patients with and without T2D. It is worth mentioning that due to its positive chronotropic effect, treatment with liraglutide was associated with an increase in heart rate and more serious cardiac adverse events. ${ }^{124}$

Finally, in a large Scandinavian register-based cohort study, the use of liraglutide, as compared with the use of DPP-4 inhibitors, was associated with significantly reduced risk of major cardiovascular events, but no significant differences were identified for risk of HF. ${ }^{125}$

\section{Semaglutide}

The Trial to Evaluate Cardiovascular and Other Long-term Outcomes with Semaglutide in Subjects with Type 2 Diabetes (SUSTAIN-6) enrolled 3927 patients with T2D with established CV disease or at high $\mathrm{CV}$ risk, randomized to receive once-weekly semaglutide $(0.5 \mathrm{mg}$ or $1.0 \mathrm{mg})$ or placebo for 104 weeks. The primary outcome of $\mathrm{CV}$ death, nonfatal myocardial infarction or nonfatal stroke was significantly reduced in the semaglutide group (HR 0.74; 95\%CI 0.58-0.95; $\mathrm{P}<0.001$ for non-inferiority). No difference was found between the two groups regarding HF hospitalization (HR 1.11; 95\%CI 0.77-1.61; $\mathrm{P}=0.56$ ). ${ }^{126}$

\section{Exenatide}

The Exenatide Study of Cardiovascular Event Lowering (EXSCEL) trial enrolled 14,752 patients with T2D, of whom more than $70 \%$ had a previous established CV disease, randomized to once weekly, injectable, extended-release formulation of exenatide at a dose of $2 \mathrm{mg}$ or placebo and followed for a median of 3.2 years. ${ }^{127}$ As a result, no difference was found between exenatide and placebo in the primary composite outcome of CV death, nonfatal myocardial infarction and nonfatal stroke ( 3.7 versus 4.0 events per 100 patient-years), as well as in the secondary end- 
point of HF hospitalization ( 0.9 versus 1 events per 100 patient-years). ${ }^{128}$

However, exenatide was found to improve hemodynamic function in patients with $\mathrm{T} 2 \mathrm{D}$ and congestive HF. ${ }^{129-131}$ Moreover, a retrospective observational study showed that treatment with exenatide twice daily, in addition to oral antidiabetic drugs, was associated with a reduced risk of CV events, including $\mathrm{HF}$, compared to insulin. ${ }^{132}$

Noteworthy, the FREEDOM-CVO is an ongoing trial aimed at evaluating $\mathrm{CV}$ outcomes in patients with T2D treated with continuous subcutaneous delivery of exenatide versus placebo (ClinicalTrials.gov ID: NCT01455896).

\section{Albiglutide}

The Harmony Outcomes Trial assessed the safety and efficacy of albiglutide in 9463 patients with T2D and established CV disease randomized to a subcutaneous injection of albiglutide (30-50 mg, based on glycemic response and tolerability) or of a matched volume of placebo once a week, in addition to their standard care. The median duration of the follow up was 1.6 years. The primary composite outcome (i.e. first occurrence of $\mathrm{CV}$ death, myocardial infarction, or stroke) occurred at an incidence rate of 4.6 events per 100 person-years in the albiglutide group and at an incidence rate of 5.9 events per 100 person-years in the placebo group (HR $0.78,95 \%$ CI $0.68-0.90$; $\mathrm{P}<0.001$ for non-inferiority; $\mathrm{P}=0.0006$ for superiority). The composite secondary outcome of death from $\mathrm{CV}$ causes or hospital admission for HF did not significantly differ between the two groups (HR $0.85,95 \% \mathrm{CI}$ 0.70-1.04). ${ }^{133}$ Moreover, a randomized, placebo-controlled study in 82 patients with NYHA class II or III and LVEF $<40 \%$ found no difference between albiglutide versus placebo in change in LVEF. ${ }^{134}$

\section{Dulaglutide}

The Researching cardiovascular Events with a Weekly INcretin in Diabetes (REWIND) trial evaluated the CV safety of dulaglutide in 9901 patients with T2D with or at risk of CV disease. ${ }^{135}$

As a result, during a median follow-up of 5.4 years, the primary composite outcome of nonfatal myocardial infarction, nonfatal stroke, or CV death occurred in 594 (12.0\%) participants in the dulaglutide group and in $663(13.4 \%)$ in the placebo group (HR $0.88,95 \%$ CI $0.79-0.99 ; \mathrm{P}=0.026$ ). However, dulaglutide did not significantly affect the incidence of hospitalization for HF (HR 0.93, 95\%CI 0.77-1.12). ${ }^{136} \mathrm{In}$ addition, an exploratory analysis from the REWIND found that long-term use of dulaglutide was associated with a decreased composite renal outcome defined as the first occurrence of new macroalbuminuria, a sus- tained decline in eGFR of $30 \%$ or more from baseline, or chronic renal replacement therapy (HR 0.85, $95 \%$ CI $0.77-0.93 ; \mathrm{P}=0.0004) .{ }^{137}$

\section{SGLT2 inhibitors}

Sodium-glucose co-transporter 2 (SGLT2) inhibitors are a new class of antidiabetic drugs that block the SGLT2 receptor, which is located in the proximal tubule of the kidney and it is responsible for $90 \%$ of renal glucose reabsorption, with consequent increase in renal glucose excretion. They include four oral agents (canagliflozin, dapagliflozin, empagliflozin, and ertugliflozin) approved for the treatment of T2D by FDA and the European Medicines Agency, either as monotherapy or in combination with other glucoselowering drug classes. They are effective in lowering fasting blood glucose and $\mathrm{HbA}_{1 \mathrm{c}}$ levels; moreover, they induce loss of weight. In general, they are well tolerated and have a low hypoglycemia risk in patients not using sulfonylureas or insulin. ${ }^{138}$ Adverse effects include hypotension, dehydration, increased risk of urinary and genital infections and euglycemic ketoacidosis.

\section{Empagliflozin}

The Empagliflozin Cardiovascular Outcome Event Trial in Type 2 Diabetes Mellitus Patients - Removing Excess Glucose (EMPA-REG OUTCOME) explored the effects of empagliflozin in addition to standard care on $\mathrm{CV}$ morbidity and mortality in 7020 patients with T2D at high CV risk. As compared with placebo, empagliflozin resulted in a significantly lower risk of death from CV causes (HR 0.62; 95\%CI 0.49-0.77; $\mathrm{P}<0.001$ ), death from any causes (HR 0.68; $95 \% \mathrm{CI} 0.57-0.82$; $\mathrm{P}<0.001)$ and hospitalization for $\mathrm{HF}$ (HR $0.65 ; 95 \% \mathrm{CI}$ $0.50-0.85$; $\mathrm{P}=0.002),{ }^{139}$ with a consistent benefit observed in patients with and without $\mathrm{HF}$ at baseline. ${ }^{140}$ In addition, a subsequent analysis regarding long-term renal effects showed that empagliflozin was associated with slower progression of kidney disease and lower rates of clinically relevant renal events compared to placebo. ${ }^{141}$ Further analyses confirmed that the reduction in $\mathrm{CV}$ outcome and mortality with empagliflozin $v s$ placebo was consistent across the spectrum of HF and CV risk. ${ }^{142,143}$ Moreover, empagliflozin was found to reduce the risk of additional HF-related outcomes (specifically, first introduction of loop diuretic, the composite outcome of first introduction of loop diuretic or first HF hospitalization, first mention of edema, and first investigator-reported HF) regardless of HF status at baseline ${ }^{144}$ Furthermore, a post-hoc analysis including 221 patients hospitalized for $\mathrm{HF}$ at least once, found that empagliflozin was associated with a lower risk of post-acute HF re-hospitalization and mortality as compared with placebo. ${ }^{145}$ 
Consistently, several translational studies over the past couple of years showed that empagliflozin improves cardiorespiratory fitness in patients with T2D. ${ }^{146,147}$ In addition, empagliflozin was found to cause pleiotropic effect on the myocardium by improving diastolic stiffness and function in experiments with in toto-isolated human systolic end-stage HF ventricular trabeculae. ${ }^{148}$ Moreover, in a pilot study enrolling T2D patients with symptomatic HF, empagliflozin was found to improve 1-month exercise capacity. ${ }^{149}$ Furthermore, using two commercial and one federal (Medicare) US claims data sources, empagliflozin was recently found to significantly reduce the risk of HF hospitalization compared to sitagliptin (the EMPRISE STUDY). ${ }^{150}$

Noteworthy, the following trials are ongoing:

- Renal and Cardiovascular Effects of SGLT2 inhibition in combination with loop Diuretics in diabetic patients with Chronic Heart Failure (RECEDE-CHF): to assess the effect of empagliflozin used in combination with a loop diuretic on urine output, glomerular filtration rate, cystatin $\mathrm{C}$, urinary sodium excretion, urinary protein/creatinine ratio and urinary albumin/creatinine ratio when compared with placebo in 34 participants with stable T2D and congestive HF (ClinicalTrials.gov, ID: NCT03226457); ${ }^{151}$

- EMPagliflozin outcomE tRial in Patients With chrOnic heaRt Failure with Reduced Ejection Fraction (EMPEROR-Reduced): to evaluate efficacy and safety of empagliflozin versus placebo on top of guideline-directed medical therapy in patients with HFrEF (ClinicalTrials.gov, ID: NCT03057977);

- EMPagliflozin outcomE tRial in Patients With chrOnic heaRt Failure with Preserved Ejection Fraction (EMPEROR-Preserved): to evaluate efficacy and safety of empagliflozin versus placebo on top of guideline-directed medical therapy in patients with HFpEF (ClinicalTrials.gov, ID: NCT03057951). ${ }^{152}$

\section{Canagliflozin}

The Canagliflozin Cardiovascular Assessment Study (CANVAS) ${ }^{153}$ and the CANVAS-Renal (CANVAS-R) $)^{154}$ are two sister trials designed to assess the cardiovascular safety and efficacy of canagliflozin. In an integrated analysis of the two trials as CANVAS Program, ${ }^{155}$ involving 10,142 patients with T2D and at high CV risk, canagliflozin was associated with a lower risk of $\mathrm{CV}$ events as composite outcome including death from $\mathrm{CV}$ causes, nonfatal myocardial infarction and nonfatal stroke (HR 0.86, 95\% CI 0.75-9.97, $\mathrm{P}<0.001$ for non-inferiority and $\mathrm{P}=0.002$ for superiority). Moreover, it was also significantly associated with a lower risk of HF hospitalization (HR 0.67,
95\%CI 0.52-0.87). ${ }^{156}$ Subsequent analyses demonstrated that the results were consistent across a broad range of different patient subgroups ${ }^{157}$ and that canagliflozin significantly reduced the risk of HF with no clear difference in effect on HFrEF versus $\mathrm{EFpHF}$ events. ${ }^{158}$

Noteworthy, results from the CANVAS Program also showed a possible benefit of canagliflozin on the progression of albuminuria (HR $0.73 ; 95 \% \mathrm{CI}, 0.67$ 0.79 ) and the composite outcome of a sustained $40 \%$ reduction in the estimated glomerular filtration rate, the need for renal-replacement therapy, or death from renal causes (hazard ratio, $0.60 ; 95 \% \mathrm{CI}, 0.47$ to 0.77). ${ }^{156}$ Recently, a pre-specified exploratory analysis from the CANVAS on the long-term renal effect of canagliflozin showed that the composite outcome of sustained doubled creatinine, end-stage kidney disease or renal death occurred less frequently in the canagliflozin group compared to placebo (HR 0.53, 95\%CI 0.33-0.84). In addition, annual eGFR decline was slower (slope difference $1.2 \mathrm{~mL} / \mathrm{min} / 1.73$ $\mathrm{m}^{2} /$ year, $95 \%$ CI $1.0-1.4$ ) and mean urinary albumin:creatinine ratio was $18 \%$ lower $(95 \% \mathrm{CI}$ $16 \%-20 \%$ ) in participants treated with canagliflozin compared to placebo. Overall, these results support a possible renoprotective effect in people with T2D. ${ }^{159}$ Besides, a further analysis from the CANVAS demonstrated that the beneficial effects of canagliflozin on $\mathrm{CV}$ and renal outcomes were independent of baseline renal function. ${ }^{160}$

Furthermore, the Canagliflozin and Renal Endpoints in Diabetes with Established Nephropathy Clinical Evaluation (CREDENCE) Study compared the efficacy and safety of canagliflozin versus placebo at preventing clinically important kidney and CV outcomes in 4,401 patients with T2D and albuminuric CKD. The primary outcome was a composite of endstage kidney disease (dialysis, transplantation, or a sustained estimated GFR of $<15 \mathrm{~mL}$ per minute per $1.73 \mathrm{~m}^{2}$ ), a doubling of the serum creatinine level, or death from renal or cardiovascular causes. The relative risk of the primary outcome was $30 \%$ lower in the canagliflozin group than in the placebo group, with event rates of 43.2 and 61.2 per 1000 patient-years, respectively (HR 0.70; 95\%CI 0.59-0.82; $\mathrm{P}=0.00001$ ). The relative risk of the renal-specific composite of end-stage kidney disease (ESKD), a doubling of the creatinine level, or death from renal causes was 34\% lower (HR 0.66 ; 95\%CI $0.53-0.81 ; \mathrm{P}<0.001$ ), and the relative risk of end-stage kidney disease was $32 \%$ lower (HR 0.68; 95\%CI 0.54 to $0.86 ; \mathrm{P}=0.002$ ). The canagliflozin group also had a lower risk of $\mathrm{CV}$ death, myocardial infarction, or stroke (hazard ratio, 0.80; $95 \% \mathrm{CI}, 0.67$ to $0.95 ; \mathrm{P}=0.01$ ) and hospitalization for HF (HR 0.61; 95\%CI 0.47 to $0.80 ; \mathrm{P}<0.001$ ). ${ }^{161}$

Evidence from observational trials substantially 
confirmed the results from randomized control trials (RCTs). In particular, a meta-analysis of four observational databases (OBSERVE $4 \mathrm{D}$ ) found that canagliflozin and other SGLT2i significantly reduce the risk of HF hospitalization for HF. ${ }^{162}$ Also, a large retrospective cohort study found that canagliflozin was associated with a lower risk of HF admission to hospital and with a similar risk of stroke or myocardial infarction compared to other antidiabetic drugs (DPP4 I, GLP-1a and sulfonylureas). ${ }^{163}$ Finally, canagliflozin was found to improve left ventricular diastolic function in patients with T2D. ${ }^{164}$

Of note, the CANDLE is an ongoing study aimed at evaluating the safety and non-inferiority of canagliflozin as compared with glimepiride in patients with T2D with chronic HF. ${ }^{165}$

\section{Dapagliflozin}

The Multicenter Trial to Evaluate the Effect of Dapagliflozin on the Incidence of Cardiovascular EventsThrombolysis In Myocardial Infarction Study Group 58 (DECLARE-TIMI 58) evaluated the safety and efficacy of dapagliflozin in 17,160 patients with T2D and established CV diseases or at high CV risk. Dapagliflozin resulted non-inferior to placebo regarding the primary composite outcome (i.e., time to the first event of $\mathrm{CV}$ death, myocardial infarction, or ischemic stroke; HF 0.93 ; $95 \% \mathrm{CI} 0.84-1.03$; $\mathrm{P}=0.17$ for superiority; $\mathrm{P}<0.001$ for non-inferiority) and it was associated with a lower rate of hospitalization for HF (HR $0.73 ; 95 \%$ CI 0.61-0.88). ${ }^{166}$ Moreover, the incidence of a secondary renal composite outcome $(\geq 40 \%$ decrease in eGFR to $<60 \mathrm{~mL}$ per minute per $1.73 \mathrm{~m}^{2}$ of bodysurface area, new ESKD, or death from renal or CV causes) was $4.3 \%$ in the dapagliflozin group and $5.6 \%$ in the placebo group (HF $0.76 ; 95 \% \mathrm{CI} 0.67-0.87$ ).

In addition, subsequent analyses found that the risk reduction of $\mathrm{CV}$ death and $\mathrm{HF}$ hospitalization were even greater benefits in patients with $\mathrm{T} 2 \mathrm{D}$ and prior myocardial infarction ${ }^{167}$ and in patients with HFrEF than in those without. ${ }^{168}$

Consistently, in a real-world population similar to the one included in the DECLARE-TIMI 58 study, dapagliflozin showed CV safety and resulted in lower event rates of HF hospitalization and CV mortality versus other glucose-lowering drugs. ${ }^{169}$ Moreover, in another study dapagliflozin was associated with a lower risk of MACE, HF hospitalization and all-cause mortality compared with DPP-4 inhibitors. ${ }^{170}$ Finally, dapagliflozin was found to significantly improve the left ventricular diastolic function in patients with T2D and $\mathrm{HF}$ after 6 months of treatment. ${ }^{171}$

Noteworthy, the following trials are ongoing:

- An Exploratory Study of Dapagliflozin for the Attenuation of Albuminuria in Patients with Heart Failure and Type 2 Diabetes Mellitus (DAPPER): to evaluate whether dapagliflozin decreases albuminuria and exerts cardioprotective effects in $\mathrm{Pa}-$ tients with T2D and HF. ${ }^{172}$

- Study to Evaluate the Effect of Dapagliflozin on the Incidence of Worsening Heart Failure or Cardiovascular Death in Patients with Chronic Heart Failure (DAPA-HF): to evaluate the effect of dapagliflozin on the incidence of worsening HF or CV death in patients with HFrEF (ClinicalTrials. gov, ID: NCT03036124). ${ }^{173}$

- Dapagliflozin Evaluation to Improve the LIVEs of Patients with PReserved Ejection Fraction Heart Failure (DELIVER): to evaluate the effect of dapagliflozin $10 \mathrm{mg}$ versus placebo once daily in reducing the composite of $\mathrm{CV}$ death or heart failure events in patients with HFpEF (hospitalizations for HF or urgent HF visits) (ClinicalTrials.gov, ID: NCT03619213).

\section{Ertugliflozin}

VERTIS-CV is an ongoing trial to assess the cardiovascular safety of ertugliflozin in patients with T2D and established CVD (ClinicalTrials.gov, ID: NCT01986881). ${ }^{174}$

\section{Sotagliflozin}

The Effect of Sotagliflozin on Cardiovascular Events in Patients with Type 2 Diabetes Post Worsening Heart Failure (SOLOIST-WHF) Trial is an ongoing study aimed at demonstrating that:

- sotagliflozin reduces CV mortality and morbidity (composite of $\mathrm{CV}$ death or HF hospitalization) compared to placebo in hemodynamically stable patients with T2D and LVEF $<50 \%$ after admission for worsening heart failure (WHF);

- sotagliflozin reduces CV mortality and morbidity (composite of CV death or HF hospitalization) compared to placebo in hemodynamically stable patients with T2D and HF irrespective of LVEF after admission for WHF (ClinicalTrials.gov, ID: NCT03521934).

\section{Discussion}

The main innovation concerning the treatment of patients with T2D and HF comes from studies on new glucose-lowering drugs. In particular, some robust and consistent evidence suggests a beneficial effect of all SGLT2 inhibitors in reducing the risk of hospitalization for HF in patients with T2D (Table 199,102-104,110$112,117,119,120,126-128,133,135,136,139,155,156,161,166,174)$. Consistently, in the Comparative Effectiveness of Cardiovascular Outcomes in New Users of Sodium-Glucose Cotransporter-2 Inhibitors (CVD-REAL) Study examining real-word data (medical claims, primary care/hospital 


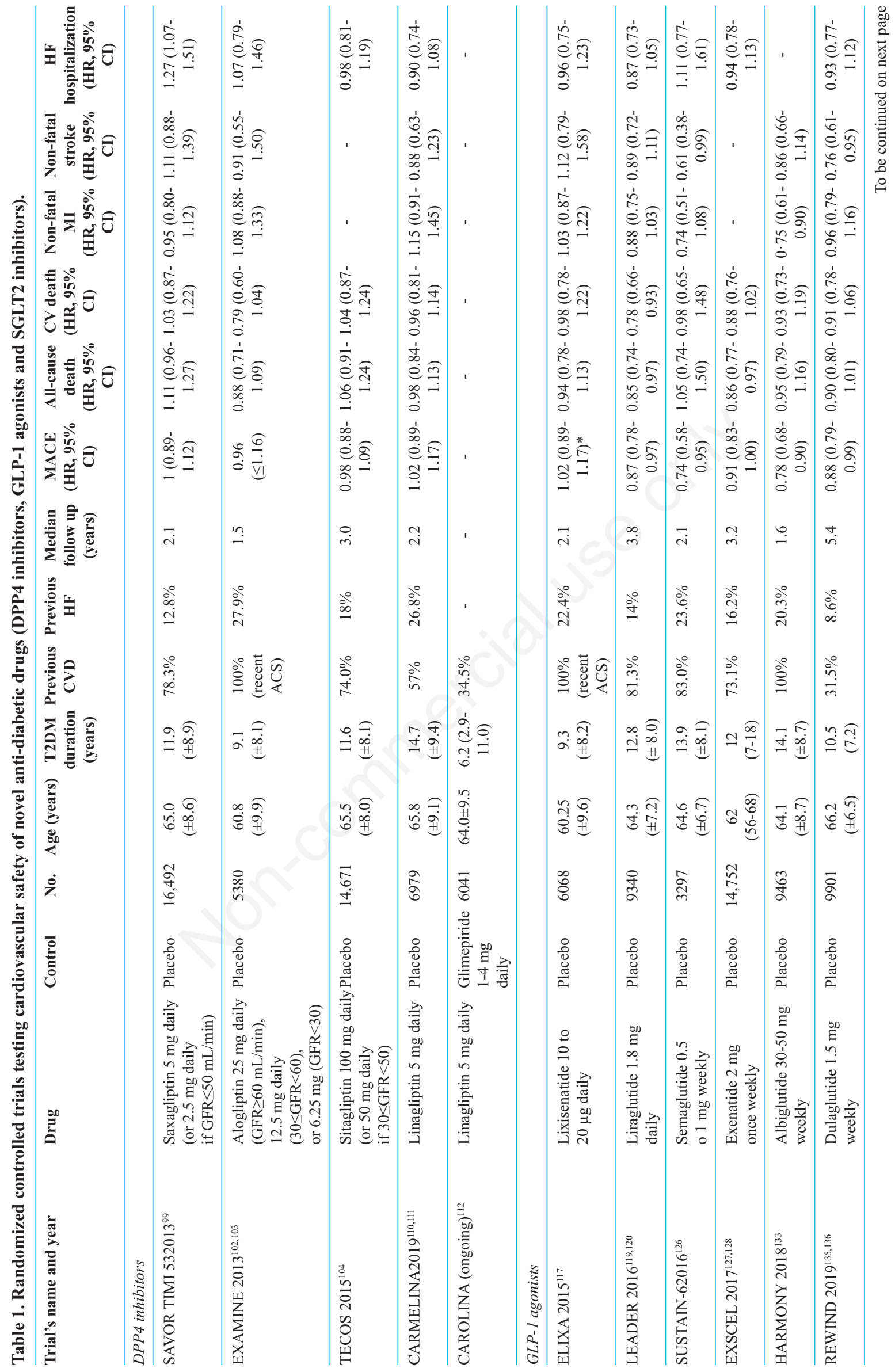




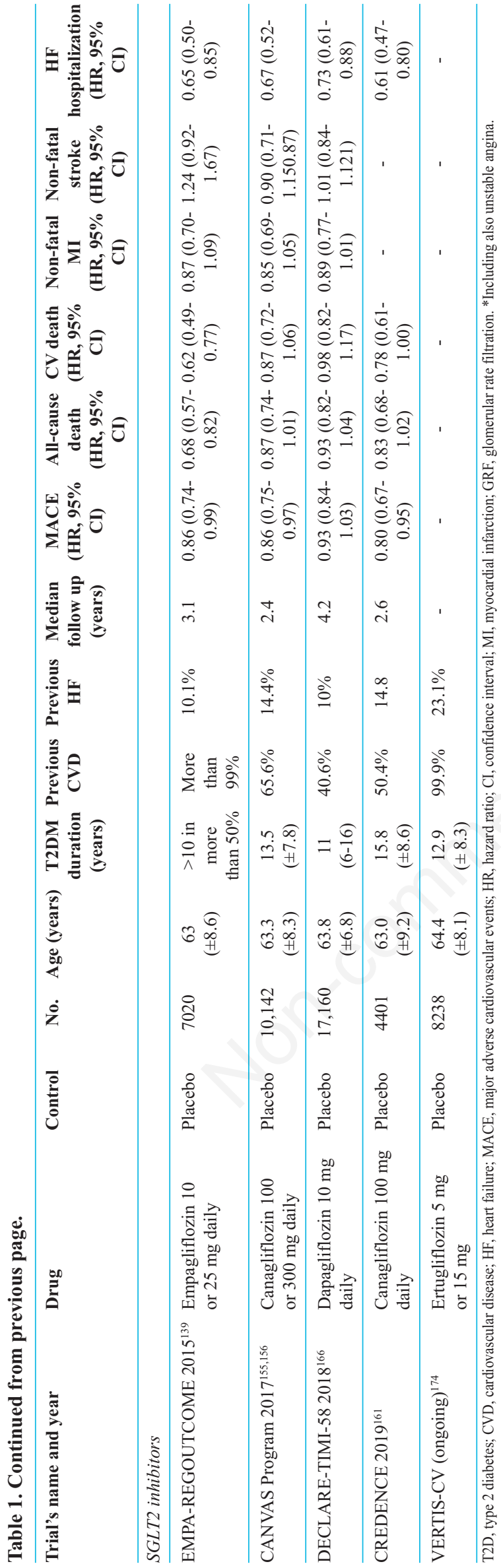

records, and national registries) from the United States, Norway, Denmark, Sweden, Germany, and the United Kingdom, SGLT2 inhibitors were associated with a lower risk of death and HF hospitalization compared to other glucose-lowering drugs. ${ }^{175}$ The subsequent CVD-REAL 2 study, enrolling T2D patients from Asia Pacific, Middle East and North America, confirmed this finding. ${ }^{176}$

The plausible underlying mechanism seems to relate to their natriuretic effect with consequent decrease in fluid overload and improvement of congestive symptoms. ${ }^{177}$ Over the past decade, several trials have been developed to test the efficacy and safety of SGLT2 inhibitors. Four of them, including EMPAREG-OUTCOME (empagliflozin), CANVAS Program (canagliflozin), DECLARE-TIMI 58 (depagliflozin) and CREDENCE (canagliflozin) have been completed and they consistently showed a significant reduction in HF hospitalization, suggesting the existence of a possible class effect. Ongoing trials specifically enrolling patients with HF (Table $2^{165,172,173}$ ) will provide further information, especially whether these drugs may be used also in patients without T2D and with acute HF decompensation. ${ }^{178}$

Interestingly, a renal-protective effect of SGLT2 inhibitors was also suggested. In fact, RCTs (EMAPREGOUTCOME, CANVAS Program and DECLARETIMI 58) consistently demonstrated that SGLT2 inhibitors significantly reduce renal events in patients with T2D when compared to placebo (Table

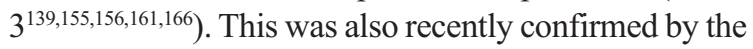
CREDENCE trial, which was specifically designed to test renal outcomes in patients with T2D and nephropathy and, therefore, included only participants with impaired renal function (eGFR of 30 to $<90 \mathrm{~mL}$ per minute per $1.73 \mathrm{~m}^{2}$ of body-surface area). However, we need to mention that patients with severe or end-stage CKD were excluded from RCTs. Specifically, the exclusion criteria were $\mathrm{CrCl}<60 \mathrm{~mL} / \mathrm{min}$ (estimated using the Cockroft-Gault equation) for the DECLARE-TIMI 58; eGFR $<30 \mathrm{~mL} / \mathrm{min} / 1.73 \mathrm{~m}^{2}$ (estimated using the MDRD formula) for the other trials (Table 3).

Noteworthy, in a recent metanalysis including data from the EMPAREG-OUTCOME, CANVAS Program and DECLARE-TIMI 58, Zelniker and colleagues confirmed that SGLT2i reduced the risk of hospitalization for HF and progression of renal disease regardless of existing atherosclerotic $\mathrm{CV}$ disease or a history of HF. However, an interaction between baseline renal function and the clinical benefit of SGLT2 inhibition was observed. In particular, they found a lesser reduction in progression of renal disease but a greater reduction in hospitalization for HF with SGLT2 inhibition in patients with worse baseline renal function. ${ }^{179}$ Although the exact mechanisms underlying this interaction are not fully understood, the 


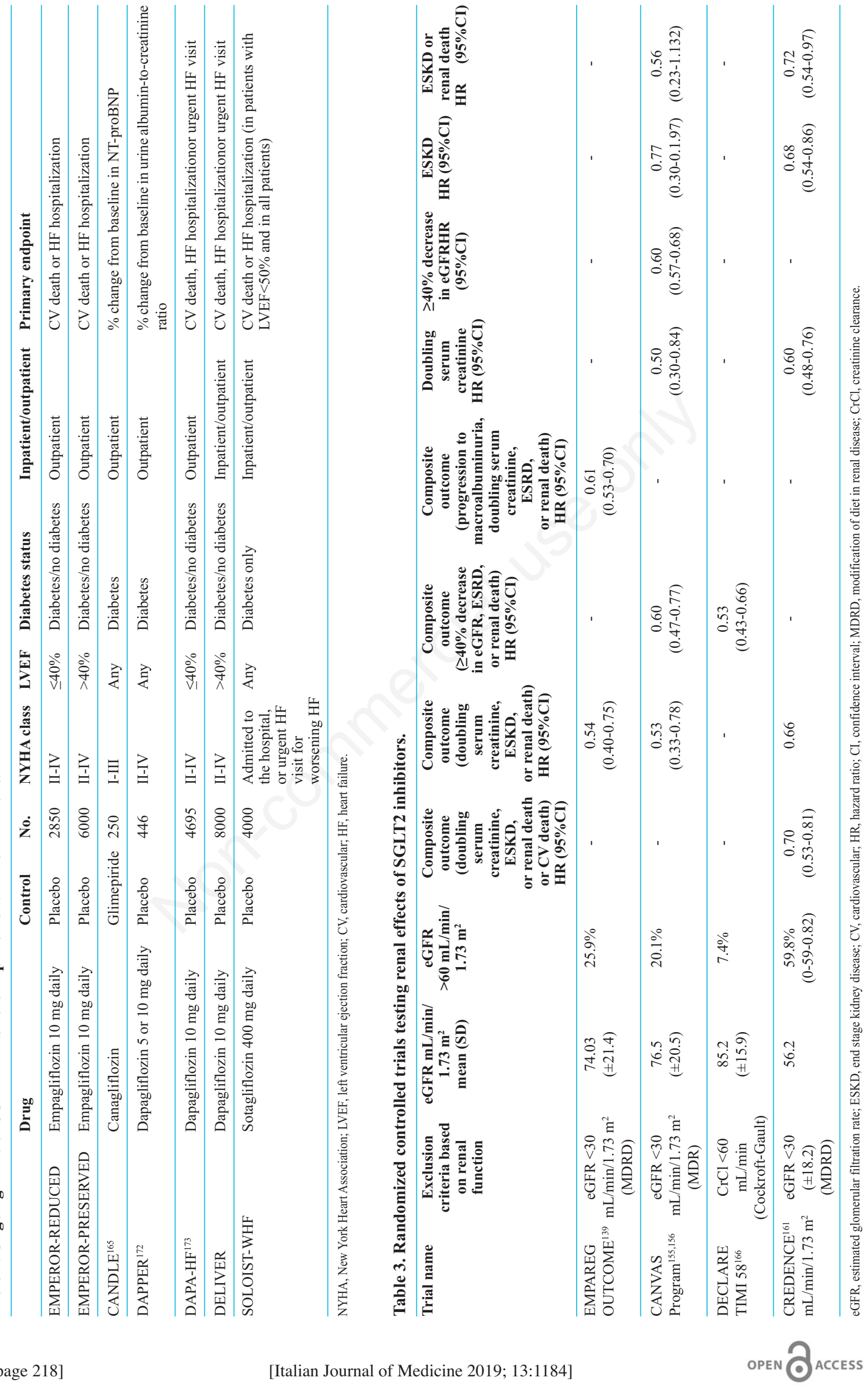


authors suggest that patients with worse baseline renal function are at higher risk of HF hospitalization and therefore this susceptible population may have a particular benefit from SGLT2i' renoprotective effect and natriuresis, that largely explain their association with the reduction in HF hospitalization.

\section{Conclusions}

In conclusion, SGLT2 inhibitors appear to be a promising drug to treat patients with T2D and HF. Ongoing RCTs specifically enrolling patients with HF treated with SGLT2 inhibitors will provide more insights on the underlying mechanisms and further information about their indications and safety.

\section{References}

1. Ponikowski P, Voors AA, Anker SD, et al. 2016 ESC Guidelines for the diagnosis and treatment of acute and chronic heart failure: The Task Force for the diagnosis and treatment of acute and chronic heart failure of the European Society of Cardiology (ESC). Developed with the special contribution of the Heart Failure Association (HFA) of the ESC. Eur J Heart Fail 2016;18:891-975.

2. Classification and Diagnosis of Diabetes: Standards of Medical Care in Diabetes -2018 American Diabetes Association Diabetes Care 2018;41:S13-27.

3. Associazione Medici Diabetologi (AMD) - Società Italiana di Diabetologia (SID). Standard Italiani per la cura del diabete mellito 2018. Available from: http://www.siditalia.it/pdf/Standard\%20di\%20Cura \%20 AMD \%20-\%20SID\%202018 protetto2.pdf

4. Seferović PM, Petrie MC, Filippatos GS, et al. Type 2 diabetes mellitus and heart failure: a position statement from the Heart Failure Association of the European Society of Cardiology. Eur J Heart Fail 2018;20:853-72.

5. Khan H, Anker SD, Januzzi JL Jr, et al. Heart failure epidemiology in patients with diabetes mellitus without coronary heart disease. J Card Fail 2019;25:78-86.

6. Thrainsdottir IS, Aspelund T, Thorgeirsson G, et al. The association between glucose abnormalities and heart failure in the population-based Reykjavik study. Diabetes Care 2005;28:612-6.

7. McMurray JJ, Gerstein HC, Holman RR, Pfeffer MA. Heart failure: a cardiovascular outcome in diabetes that can no longer be ignored. Lancet Diabetes Endocrinol 2014;2:843-51.

8. Dei Cas A, Khan SS, Butler J, et al. Impact of diabetes on epidemiology, treatment, and outcomes of patients with heart failure. JACC Heart Fail 2015;3:136-45.

9. Jia G, Whaley-Connell A, Sowers JR. Diabetic cardiomyopathy: a hyperglycaemia- and insulin-resistanceinduced heart disease. Diabetologia 2018;61:21-8.

10. Levelt E, Gulsin G, Neubauer S, McCann GP. MECHANISMS IN ENDOCRINOLOGY: Diabetic cardiomyopathy: pathophysiology and potential metabolic interventions state of the art review. Eur J Endocrinol 2018;178:R127-39.

11. SOLVD Investigators, Yusuf S, Pitt B, Davis CE, et al. Effect of enalapril on survival in patients with reduced left ventricular ejection fractions and congestive heart failure. N Engl J Med 1991;325:293-302.

12. SOLVD Investigators, Yusuf S, Pitt B, Davis CE, et al. Effect of enalapril on mortality and the development of heart failure in asymptomatic patients with reduced left ventricular ejection fractions. N Engl J Med 1992;327:685-91.

13. Rørth R, Jhund PS, Mogensen UM, et al. Risk of incident heart failure in patients with diabetes and asymptomatic left ventricular systolic dysfunction. Diabetes Care 2018;41:1285-91.

14. Rydén L, Armstrong PW, Cleland JG, et al. Efficacy and safety of high-dose lisinopril in chronic heart failure patients at high cardiovascular risk, including those with diabetes mellitus. Results from the ATLAS trial. Eur Heart J 2000;21:1967-78.

15. Shekelle PG, Rich MW, Morton SC, et al. Efficacy of angiotensin-converting enzyme inhibitors and betablockers in the management of left ventricular systolic dysfunction according to race, gender, and diabetic status: a meta-analysis of major clinical trials. J Am Coll Cardiol 2003;41:1529-38.

16. Vermes E, Ducharme A, Bourassa MG, et al. Enalapril reduces the incidence of diabetes in patients with chronic heart failure: insight from the Studies Of Left Ventricular Dysfunction (SOLVD). Circulation 2003;107:1291-6.

17. Cohn JN, Tognoni G; Valsartan Heart Failure Trial Investigators. A randomized trial of the angiotensin-receptor blocker valsartan in chronic heart failure. N Engl J Med 2001;345:1667-75.

18. Maggioni AP, Anand I, Gottlieb SO, et al. Effects of valsartan on morbidity and mortality in patients with heart failure not receiving angiotensin-converting enzyme inhibitors. J Am Coll Cardiol 2002;40:1414-21.

19. Pfeffer MA, Swedberg K, Granger CB, et al. Effects of candesartan on mortality and morbidity in patients with chronic heart failure: the CHARM-Overall programme. Lancet 2003;362:759-66.

20. MacDonald MR, Petrie MC, Varyani F, et al. Impact of diabetes on outcomes in patients with low and preserved ejection fraction heart failure: an analysis of the Candesartan in Heart failure: Assessment of Reduction in Mortality and morbidity (CHARM) programme. Eur Heart J 2008;29:1377-85.

21. McMurray JJ, Ostergren J, Swedberg K, et al. Effects of candesartan in patients with chronic heart failure and reduced left-ventricular systolic function taking angiotensin-converting-enzyme inhibitors: the CHARM-Added trial. Lancet 2003;362:767-71.

22. Brenner BM, Cooper ME, de Zeeuw D, et al. Effects of losartan on renal and cardiovascular outcomes in patients with type 2 diabetes and nephropathy. N Engl J Med 2001;345:861-9.

23. Konstam MA, Neaton JD, Dickstein K, et al. Effects of high-dose versus low-dose losartan on clinical outcomes in patients with heart failure (HEAAL study): a randomised, double-blind trial. Lancet 2009;374:1840-8.

24. Carr AA, Kowey PR, Devereux RB, et al. Hospitalizations for new heart failure among subjects with diabetes mellitus in the RENAAL and LIFE studies. Am J Cardiol 2005;96:1530-6.

25. Yusuf S, Ostergren JB, Gerstein HC, et al. Effects of candesartan on the development of a new diagnosis of diabetes mellitus in patients with heart failure. Circulation 2005;112:48-53. 
26. Parving HH, Brenner BM, McMurray JJ, et al. Cardiorenal end points in a trial of aliskiren for type 2 diabetes. N Engl J Med 2012;367:2204-13.

27. Gheorghiade M, Böhm M, Greene SJ, et al. Effect of aliskiren on postdischarge mortality and heart failure readmissions among patients hospitalized for heart failure: the ASTRONAUT randomized trial. JAMA 2013;309:1125-35.

28. McMurray JJ, Krum H, Abraham WT, et al. Aliskiren, Enalapril, or Aliskiren and Enalapril in Heart Failure. N Engl J Med 2016;374:1521-32.

29. Kristensen SL, Mogensen UM, Tarnesby G, et al. Aliskiren alone or in combination with enalapril vs. enalapril among patients with chronic heart failure with and without diabetes: a subgroup analysis from the ATMOSPHERE trial. Eur J Heart Fail 2018;20:136-47.

30. Deedwania PC, Giles TD, Klibaner M, et al. Efficacy, safety and tolerability of metoprolol $\mathrm{CR} / \mathrm{XL}$ in patients with diabetes and chronic heart failure: experiences from MERIT-HF. Am Heart J 2005;149:159-67.

31. The Cardiac Insufficiency Bisoprolol Study II (CIBISII): a randomised trial. Lancet 1999;353:9-13.

32. Erdmann E, Lechat P, Verkenne P, Wiemann H. Results from post-hoc analyses of the CIBIS II trial: effect of bisoprolol in high-risk patient groups with chronic heart failure. Eur J Heart Fail 2001;3:469-79.

33. Packer M, Fowler MB, Roecker EB, et al. Effect of carvedilol on the morbidity of patients with severe chronic heart failure: results of the carvedilol prospective randomized cumulative survival (COPERNICUS) study. Circulation 2002;106:2194-9.

34. Krum H, Roecker EB, Mohacsi P, et al. Effects of initiating carvedilol in patients with severe chronic heart failure: results from the COPERNICUS Study. JAMA 2003;289:712-8.

35. Nodari S, Metra M, Dei Cas A, Dei Cas L. Efficacy and tolerability of the long-term administration of carvedilol in patients with chronic heart failure with and without concomitant diabetes mellitus. Eur J Heart Fail 2003;5:803-9.

36. Poole-Wilson PA, Swedberg K, Cleland JG, et al. Comparison of carvedilol and metoprolol on clinical outcomes in patients with chronic heart failure in the Carvedilol Or Metoprolol European Trial (COMET): randomised controlled trial. Lancet 2003;362:7-13.

37. Torp-Pedersen C, Metra M, Charlesworth A, et al. Effects of metoprolol and carvedilol on pre-existing and new onset diabetes in patients with chronic heart failure: data from the Carvedilol Or Metoprolol European Trial (COMET). Heart 2007;93:968-73.

38. Haas SJ, Vos T, Gilbert RE, Krum H. Are beta-blockers as efficacious in patients with diabetes mellitus as in patients without diabetes mellitus who have chronic heart failure? A meta-analysis of large-scale clinical trials. Am Heart J 2003;146:848-53.

39. Bell DS, Lukas MA, Holdbrook FK, Fowler MB. The effect of carvedilol on mortality risk in heart failure patients with diabetes: results of a meta-analysis. Curr Med Res Opin 2006;22:287-96.

40. Wai B, Kearney LG, Hare DL, et al. Beta blocker use in subjects with type 2 diabetes mellitus and systolic heart failure does not worsen glycaemic control. Cardiovasc Diabetol 2012;11:14.

41. Witte KK, Drozd M, Walker AMN, et al. Mortality re- duction associated with $\beta$-adrenoceptor inhibition in chronic heart failure is greater in patients with diabetes. Diabetes Care 2018;41:136-42.

42. Pitt B, Zannad F, Remme WJ, et al. The effect of spironolactone on morbidity and mortality in patients with severe heart failure. Randomized Aldactone Evaluation Study Investigators. N Engl J Med 1999;341:709-17.

43. Zannad F, McMurray JJ, Krum H, et al. Eplerenone in patients with systolic heart failure and mild symptoms. N Engl J Med 2011;364:11-21.

44. Preiss D, van Veldhuisen DJ, Sattar N, et al. Eplerenone and new-onset diabetes in patients with mild heart failure: results from the Eplerenone in Mild Patients Hospitalization and Survival Study in Heart Failure (EMPHASIS-HF). Eur J Heart Fail 2012;14:909-15.

45. Pitt B, Anker SD, Böhm M, et al. Rationale and design of MinerAlocorticoid Receptor antagonist Tolerability Study-Heart Failure (ARTS-HF): a randomized study of finerenone vs. eplerenone in patients who have worsening chronic heart failure with diabetes and/or chronic kidney disease. Eur J Heart Fail 2015;17:224-32.

46. Filippatos G, Anker SD, Böhm M, et al. A randomized controlled study of finerenone vs. eplerenone in patients with worsening chronic heart failure and diabetes mellitus and/or chronic kidney disease. Eur Heart J 2016;37:2105-14.

47. McMurray JJ, Packer M, Desai AS, et al. Angiotensinneprilysin inhibition versus enalapril in heart failure. $\mathrm{N}$ Engl J Med 2014;371:993-1004.

48. Kristensen SL, Preiss D, Jhund PS, et al. Risk related to pre-diabetes mellitus and diabetes mellitus in heart failure with reduced ejection fraction: insights from prospective comparison of ARNI With ACEI to Determine Impact on Global Mortality and Morbidity in Heart Failure Trial. Circ Heart Fail 2016;9.

49. Seferovic JP, Claggett B, Seidelmann SB, et al. Effect of sacubitril/valsartan versus enalapril on glycaemic control in patients with heart failure and diabetes: a posthoc analysis from the PARADIGM-HF trial. Lancet Diabetes Endocrinol 2017;5:333-40.

50. McMurray JJ, Holman RR, Haffner SM, et al. Effect of valsartan on the incidence of diabetes and cardiovascular events. N Engl J Med 2010;362:1477-90.

51. van der Zij1 NJ, Moors CC, Goossens GH, et al. Valsartan improves \{beta\}-cell function and insulin sensitivity in subjects with impaired glucose metabolism: a randomized controlled trial. Diabetes Care 2011;34:845-51.

52. Plamboeck A, Holst JJ, Carr RD, Deacon CF. Neutral endopeptidase 24.11 and dipeptidyl peptidase IV are both mediators of the degradation of glucagon-like peptide 1 in the anaesthetised pig. Diabetologia 2005;48:1882-90.

53. Packer M. Augmentation of glucagon-like peptide-1 receptor signalling by neprilysin inhibition: potential implications for patients with heart failure. Eur J Heart Fail 2018;20:973-7.

54. Willard JR, Barrow BM, Zraika S. Improved glycaemia in high-fat-fed neprilysin-deficient mice is associated with reduced DPP-4 activity and increased active GLP1 levels. Diabetologia 2017;60:701-8.

55. Birkenfeld AL, Boschmann M, Moro C, et al. Lipid mobilization with physiological atrial natriuretic peptide concentrations in humans. J Clin Endocrinol Metab 2005;90:3622-8. 
56. Birkenfeld AL, Budziarek P, Boschmann M, et al. Atrial natriuretic peptide induces postprandial lipid oxidation in humans. Diabetes 2008;57:3199-204.

57. Engeli S, Birkenfeld AL, Badin PM, et al. Natriuretic peptides enhance the oxidative capacity of human skeletal muscle. J Clin Invest 2012;122:4675-9.

58. Coué M, Badin PM, Vila IK, et al. Defective natriuretic peptide receptor signaling in skeletal muscle links obesity to type 2 diabetes. Diabetes 2015;64:4033-45.

59. Heinisch BB, Vila G, Resl M, et al. B-type natriuretic peptide (BNP) affects the initial response to intravenous glucose: a randomised placebo-controlled cross-over study in healthy men. Diabetologia 2012;55:1400-5.

60. Lazo M, Young JH, Brancati FL, et al. NH2-terminal pro-brain natriuretic peptide and risk of diabetes. Diabetes 2013;62:3189-93.

61. Mori MA, Sales VM, Motta FL, et al. Kinin B1 receptor in adipocytes regulates glucose tolerance and predisposition to obesity. PLoS One 2012;7:e44782.

62. Solomon SD, Rizkala AR, Lefkowitz MP et al. Baseline Characteristics of Patients With Heart Failure and Preserved Ejection Fraction in the PARAGON-HF Trial. Circ Heart Fail 2018;11:e04962.

63. Taylor AL, Ziesche S, Yancy CW, et al. Early and sustained benefit on event-free survival and heart failure hospitalization from fixed-dose combination of isosorbide dinitrate/hydralazine: consistency across subgroups in the African-American Heart Failure Trial. Circulation 2007;115:1747-53.

64. Komajda M, Tavazzi L, Francq BG, et al. Efficacy and safety of ivabradine in patients with chronic systolic heart failure and diabetes: an analysis from the SHIFT trial. Eur J Heart Fail 2015; 17:1294-301.

65. UK Prospective Diabetes Study (UKPDS) Group. Intensive blood-glucose control with sulphonylureas or insulin compared with conventional treatment and risk of complications in patients with type 2 diabetes (UKPDS 33). Lancet 1998;352:837-53.

66. Action to Control Cardiovascular Risk in Diabetes Study Group. Effects of intensive glucose lowering in type 2 diabetes. N Engl J Med 2008;358:2545-59.

67. ADVANCE Collaborative Group, Intensive blood glucose control and vascular outcomes in patients with type 2 diabetes. N Engl J Med 2008;358:2560-72.

68. Duckworth W, Abraira C, Moritz T, et al. Glucose control and vascular complications in veterans with type 2 diabetes. N Engl J Med 2009;360:129-39.

69. Turnbull FM, Abraira C, Anderson RJ, et al. Intensive glucose control and macrovascular outcomes in type 2 diabetes. Diabetologia 2009;52:2288-98.

70. Boussageon R, Bejan-Angoulvant T, Saadatian-Elahi M, et al. Effect of intensive glucose lowering treatment on all cause mortality, cardiovascular death, and microvascular events in type 2 diabetes: meta-analysis of randomised controlled trials. BMJ 2011;343:d4169.

71. American Diabetes Association. 6. Glycemic targets: standards of medical care in diabetes-2018. Diabetes Care 2018;41:S55-64.

72. American Diabetes Association. 8. Pharmacologic Approaches to Glycemic Treatment: Standards of Medical Care in Diabetes-2018. Diabetes Care 2018;41:S73-85.

73. Lehrke M, Marx N. Diabetes mellitus and heart failure. Am J Med 2017;130:S40-50.
74. Aguilar D, Chan W, Bozkurt B, et al. Metformin use and mortality in ambulatory patients with diabetes and heart failure. Circ Heart Fail 2011;4:53-8.

75. Evans JM, Doney AS, AlZadjali MA, et al. Effect of Metformin on mortality in patients with heart failure and type 2 diabetes mellitus. Am J Cardiol 2010;106:1006-10.

76. Andersson C, Olesen JB, Hansen PR, et al. Metformin treatment is associated with a low risk of mortality in diabetic patients with heart failure: a retrospective nationwide cohort study. Diabetologia 2010;53:2546-53.

77. Domanski M, Krause-Steinrauf H, Deedwania P, et al. The effect of diabetes on outcomes of patients with advanced heart failure in the BEST trial. J Am Coll Cardiol 2003;42:914-22.

78. Smooke S, Horwich TB, Fonarow GC. Insulin-treated diabetes is associated with a marked increase in mortality in patients with advanced heart failure. Am Heart J 2005;149:168-74.

79. Pocock SJ, Wang D, Pfeffer MA, et al. Predictors of mortality and morbidity in patients with chronic heart failure. Eur Heart J 2006;27:65-75.

80. Mangiavacchi M, Gasparini M, Genovese S, et al. Insulin-treated type 2 diabetes is associated with a decreased survival in heart failure patients after cardiac resynchronization therapy. Pacing Clin Electrophysiol 2008;31:1425-32.

81. Gilbert RE, Krum H. Heart failure in diabetes: effects of anti-hyperglycaemic drug therapy. Lancet 2015;385:2107-17.

82. Gerstein HC, Bosch J, Dagenais GR, et al. Basal insulin and cardiovascular and other outcomes in dysglycemia. N Engl J Med 2012;367:319-28.

83. Nielsen R, Wiggers H, Thomsen HH, et al. Effect of tighter glycemic control on cardiac function, exercise capacity, and muscle strength in heart failure patients with type 2 diabetes: a randomized study. BMJ Open Diabetes Res Care 2016;4:e00202.

84. McAlister FA, Eurich DT, Majumdar SR, Johnson JA. The risk of heart failure in patients with type 2 diabetes treated with oral agent monotherapy. Eur J Heart Fail 2008;10:703-8.

85. Tzoulaki I, Molokhia M, Curcin V, et al. Risk of cardiovascular disease and all cause mortality among patients with type 2 diabetes prescribed oral antidiabetes drugs: retrospective cohort study using UK general practice research database. BMJ 2009;339:b4731.

86. Roumie CL, Min JY, D'Agostino McGowan L, et al. Comparative safety of sulfonylurea and metformin monotherapy on the risk of heart failure: a cohort study. J Am Heart Assoc 2017;6.

87. Stahn A, Pistrosch F, Ganz X, et al. Relationship between hypoglycemic episodes and ventricular arrhythmias in patients with type 2 diabetes and cardiovascular diseases: silent hypoglycemias and silent arrhythmias. Diabetes Care 2014;37:516-20.

88. Frier BM, Schernthaner G, Heller SR. Hypoglycemia and cardiovascular risks. Diabetes Care 2011;34 Suppl 2:S132-7.

89. Mellbin LG, Rydén L, Riddle MC, et al. Does hypoglycaemia increase the risk of cardiovascular events? A report from the ORIGIN trial. Eur Heart J 2013;34:3137-44.

90. Huang CJ, Wang WT, Sung SH, et al. Blood glucose reduction by diabetic drugs with minimal hypoglycaemia risk for cardiovascular outcomes: Evidence from meta- 
regression analysis of randomized controlled trials. Diabetes Obes Metab 2018;20:2131-9.

91. Jameel MN, Xiong Q, Mansoor A, et al. ATP sensitive $\mathrm{K}(+)$ channels are critical for maintaining myocardial perfusion and high energy phosphates in the failing heart. J Mol Cell Cardiol 2016;92:116-21.

92. Scognamiglio R, Avogaro A, Vigili de Kreutzenberg S, et al. Effects of treatment with sulfonylurea drugs or insulin on ischemia-induced myocardial dysfunction in type 2 diabetes. Diabetes 2002;51:808-12.

93. Holdsworth CT, Ferguson SK, Colburn TD, et al. Vascular $\mathrm{K}(\mathrm{ATP})$ channels mitigate severe muscle $\mathrm{O}(2)$ deliveryutilization mismatch during contractions in chronic heart failure rats. Respir Physiol Neurobiol 2017;238:33-40.

94. Klepzig H, Kober G, Matter C, et al. Sulfonylureas and ischaemic preconditioning; a double-blind, placebocontrolled evaluation of glimepiride and glibenclamide. Eur Heart J 1999;20:439-46.

95. Mocanu MM, Maddock HL, Baxter GF, et al. Glimepiride, a novel sulfonylurea, does not abolish myocardial protection afforded by either ischemic preconditioning or diazoxide. Circulation 2001;103:3111-6.

96. Basit A, Riaz M, Fawwad A. Glimepiride: evidencebased facts, trends, and observations (GIFTS). Vasc Health Risk Manag 2012;8:463-72.

97. Hernandez AV, Usmani A, Rajamanickam A, Moheet A. Thiazolidinediones and risk of heart failure in patients with or at high risk of type 2 diabetes mellitus: a meta-analysis and meta-regression analysis of placebocontrolled randomized clinical trials. Am J Cardiovasc Drugs 2011;11:115-28.

98. Komajda M, McMurray JJ, Beck-Nielsen H, et al. Heart failure events with rosiglitazone in type 2 diabetes: data from the RECORD clinical trial. Eur Heart J 2010;31:824-31.

99. Scirica BM, Bhatt DL, Braunwald E, et al. Saxagliptin and cardiovascular outcomes in patients with type 2 diabetes mellitus. N Engl J Med 2013;369:1317-26.

100. Scirica BM, Braunwald E, Raz I, et al. Heart failure, saxagliptin, and diabetes mellitus: observations from the SAVOR-TIMI 53 randomized trial. Circulation 2014;130:1579-88.

101. Leiter LA, Teoh H, Braunwald E, et al. Efficacy and safety of saxagliptin in older participants in the SAVORTIMI 53 trial. Diabetes Care 2015;38:1145-53.

102. White WB, Cannon CP, Heller SR, et al. Alogliptin after acute coronary syndrome in patients with type 2 diabetes. N Engl J Med 2013;369:1327-35.

103. Zannad F, Cannon CP, Cushman WC, et al. Heart failure and mortality outcomes in patients with type 2 diabetes taking alogliptin versus placebo in EXAMINE: a multicentre, randomised, double-blind trial. Lancet 2015;385:2067-76.

104. Green JB, Bethel MA, Armstrong PW, et al. Effect of sitagliptin on cardiovascular outcomes in type 2 diabetes. N Engl J Med 2015;373:232-42.

105. McGuire DK, Van de Werf F, Armstrong PW et al. Association between sitagliptin use and heart failure hospitalization and related outcomes in type 2 diabetes mellitus: secondary analysis of a randomized clinical trial. JAMA Cardiol 2016;1:126-35.

106. Krittanawong C, Kitai T, Aydar M, Sun T. Sitagliptin and risk of heart failure in patients with type 2 diabetes: a meta-analysis. JACC Heart Fail 2016;4:910.
107. Weir DL, McAlister FA, Senthilselvan A, et al. Sitagliptin use in patients with diabetes and heart failure: a population-based retrospective cohort study. JACC Heart Fail 2014;2:573-82.

108. McMurray JJV, Ponikowski P, Bolli GB, et al. Effects of vildagliptin on ventricular function in patients with type 2 diabetes mellitus and heart failure: a randomized placebo-controlled trial. JACC Heart Fail 2018;6:8-17.

109. McInnes G, Evans M, Del Prato S, et al. Cardiovascular and heart failure safety profile of vildagliptin: a metaanalysis of 17000 patients. Diabetes Obes Metab 2015; 17:1085-92.

110. Rosenstock J, Perkovic V, Johansen OE, et al. Effect of Linagliptin vs Placebo on Major Cardiovascular Events in Adults With Type 2 Diabetes and High Cardiovascular and Renal Risk: The CARMELINA Randomized Clinical Trial. JAMA 2019;321:69-79.

111. McGuire DK, Alexander JH, Johansen OE, et al. Linagliptin Effects on Heart Failure and Related Outcomes in Individuals With Type 2 Diabetes Mellitus at High Cardiovascular and Renal Risk in CARMELINA. Circulation 2019;139:351-61.

112. Marx N, Rosenstock J, Kahn SE, et al. Design and baseline characteristics of the CARdiovascular Outcome Trial of LINAgliptin Versus Glimepiride in Type 2 Diabetes (CAROLINA®). Diab Vasc Dis Res 2015;12:164-74.

113. Grigoropoulou P, Eleftheriadou I, Zoupas C, et al. Incretin-based therapies for type 2 diabetes mellitus: effects on insulin resistance. Curr Diabetes Rev 2013;9:412-7.

114. Clarke SJ, McCormick LM, Dutka DP. Optimising cardioprotection during myocardial ischaemia: targeting potential intracellular pathways with glucagon-like peptide-1. Cardiovasc Diabetol 2014;13:12.

115. Sokos GG, Nikolaidis LA, Mankad S, et al. Glucagonlike peptide-1 infusion improves left ventricular ejection fraction and functional status in patients with chronic heart failure. J Card Fail 2006;12:694-9.

116. Scheen AJ. GLP-1 receptor agonists and heart failure in diabetes. Diabetes Metab 2017;43:2S13-9.

117. Pfeffer MA, Claggett B, Diaz R, et al. Lixisenatide in patients with type 2 diabetes and acute coronary syndrome. N Engl J Med 2015;373:2247-57.

118. Seferovic JP, Bentley-Lewis R, Claggett B, et al. Retinopathy, neuropathy, and subsequent cardiovascular events in patients with type 2 diabetes and acute coronary syndrome in the ELIXA: The Importance of Disease Duration. J Diabetes Res 2018;2018:1631263.

119. Marso SP, Poulter NR, Nissen SE, et al. Design of the liraglutide effect and action in diabetes: evaluation of cardiovascular outcome results (LEADER) trial. Am Heart J 2013;166:823-30.e5.

120. Marso SP, Daniels GH, Brown-Frandsen K, et al. Liraglutide and cardiovascular outcomes in type 2 diabetes. N Engl J Med 2016;375:311-22.

121. Mann JFE, Ørsted DD, Brown-Frandsen K, et al. Liraglutide and renal outcomes in type 2 diabetes. $\mathrm{N}$ Engl J Med 2017;377:839-48.

122. Margulies KB, Hernandez AF, Redfield MM, et al. Effects of liraglutide on clinical stability among patients with advanced heart failure and reduced ejection fraction: a randomized clinical trial. JAMA 2016;316:500-8.

123. Jorsal A, Wiggers H, Holmager P, et al. A protocol for a randomised, double-blind, placebo-controlled study of 
the effect of LIraglutide on left VEntricular function in chronic heart failure patients with and without type 2 diabetes (The LIVE Study). BMJ Open 2014;4:e004885.

124. Jorsal A, Kistorp C, Holmager P, et al. Effect of liraglutide, a glucagon-like peptide-1 analogue, on left ventricular function in stable chronic heart failure patients with and without diabetes (LIVE)-a multicentre, double-blind, randomised, placebo-controlled trial. Eur J Heart Fail 2017;19:69-77.

125. Svanström H, Ueda P, Melbye M, et al. Use of liraglutide and risk of major cardiovascular events: a registerbased cohort study in Denmark and Sweden. Lancet Diabetes Endocrinol 2019;7:106-14.

126. Marso SP, Bain SC, Consoli A, et al. Semaglutide and cardiovascular outcomes in patients with type 2 diabetes. N Engl J Med 2016;375:1834-44.

127. Mentz RJ, Bethel MA, Gustavson S, et al. Baseline characteristics of patients enrolled in the Exenatide Study of Cardiovascular Event Lowering (EXSCEL). Am Heart J 2017;187:1-9.

128. Holman RR, Bethel MA, Mentz RJ, et al. Effects of once-weekly exenatide on cardiovascular outcomes in type 2 diabetes. N Engl J Med 2017;377:1228-39.

129. Best JH, Hoogwerf BJ, Herman WH, et al. Risk of cardiovascular disease events in patients with type 2 diabetes prescribed the glucagon-like peptide 1 (GLP-1) receptor agonist exenatide twice daily or other glucoselowering therapies: a retrospective analysis of the LifeLink database. Diabetes Care 2011;34:90-5.

130. Nathanson D, Ullman B, Löfström U, et al. Effects of intravenous exenatide in type 2 diabetic patients with congestive heart failure: a double-blind, randomised controlled clinical trial of efficacy and safety. Diabetologia 2012;55:926-35.

131. Nathanson D, Frick M, Ullman B, Nyström T. Exenatide infusion decreases atrial natriuretic peptide levels by reducing cardiac filling pressures in type 2 diabetes patients with decompensated congestive heart failure. Diabetol Metab Syndr 2016;8:5.

132. Paul SK, Klein K, Maggs D, Best JH. The association of the treatment with glucagon-like peptide-1 receptor agonist exenatide or insulin with cardiovascular outcomes in patients with type 2 diabetes: a retrospective observational study. Cardiovasc Diabetol 2015;14:10.

133. Hernandez AF, Green JB, Janmohamed S, et al. Albiglutide and cardiovascular outcomes in patients with type 2 diabetes and cardiovascular disease (Harmony Outcomes): a double-blind, randomised placebo-controlled trial. Lancet 2018;392:1519-29.

134. Lepore JJ, Olson E, Demopoulos L, et al. Effects of the Novel Long-Acting GLP-1 Agonist, Albiglutide, on Cardiac Function, Cardiac Metabolism, and Exercise Capacity in Patients With Chronic Heart Failure and Reduced Ejection Fraction. JACC Heart Fail 2016;4:559-66.

135. Gerstein HC, Colhoun HM, Dagenais GR, et al. Design and baseline characteristics of participants in the Researching cardiovascular Events with a Weekly INcretin in Diabetes (REWIND) trial on the cardiovascular effects of dulaglutide. Diabetes Obes Metab 2018;20:42-9.

136. Gerstein HC, Colhoun HM, Dagenais GR, et al. Dulaglutide and cardiovascular outcomes in type 2 diabetes (REWIND): a double-blind, randomized placebo-controlled trial. Lancet 2019;394:121-30.
137. Gerstein HC, Colhoun HM, Dagenais GR, et al. Dulaglutide and renal outcomes in type 2 diabetes: an exploratory analysis of the REWIND randomised, placebo-controlled trial. Lancet 2019;394:131-8.

138. van Baar MJB, van Ruiten CC, Muskiet MHA, et al. SGLT2 Inhibitors in Combination Therapy: From Mechanisms to Clinical Considerations in Type 2 Diabetes Management. Diabetes Care 2018;41:1543-56.

139. Zinman B, Wanner C, Lachin JM, et al. Empagliflozin, Cardiovascular Outcomes, and Mortality in Type 2 Diabetes. N Engl J Med 2015;373:2117-28.

140. Fitchett D, Zinman B, Wanner C, et al. Heart failure outcomes with empagliflozin in patients with type 2 diabetes at high cardiovascular risk: results of the EMPAREG OUTCOME® trial. Eur Heart J 2016;37:1526-34.

141. Wanner C, Inzucchi SE, Lachin JM, et al. Empagliflozin and Progression of Kidney Disease in Type 2 Diabetes. N Engl J Med 2016;375:323-34.

142. Fitchett D, Butler J, van de Borne P, et al. Effects of empagliflozin on risk for cardiovascular death and heart failure hospitalization across the spectrum of heart failure risk in the EMPA-REG OUTCOME® trial. Eur Heart J 2018;39:363-70.

143. Fitchett D, Inzucchi SE, Cannon CP, et al. Empagliflozin Reduced Mortality and Hospitalization for Heart Failure Across the Spectrum of Cardiovascular Risk in the EMPA-REG OUTCOME Trial. Circulation 2019;139:1384-95.

144. Januzzi J, Ferreira JP, Böhm M, et al. Empagliflozin reduces the risk of a broad spectrum of heart failure outcomes regardless of heart failure status at baseline. Eur J Heart Fail 2019;21:386-8.

145. Savarese G, Sattar N, Januzzi J, et al. Empagliflozin Is Associated With a Lower Risk of Post-Acute Heart Failure Rehospitalization and Mortality. Circulation 2019;139:1458-60.

146. Kumar N, Garg A, Bhatt DL, et al. Empagliflozin improves cardiorespiratory fitness in type 2 diabetes: translational implications. Can J Physiol Pharmacol 2018;96:1184-7.

147. Carbone S, Canada JM, Billingsley HE, et al. Effects of empagliflozin on cardiorespiratory fitness and significant interaction of loop diuretics. Diabetes Obes Metab 2018;20:2014-8.

148. Pabel S, Wagner S, Bollenberg H, et al. Empagliflozin directly improves diastolic function in human heart failure. Eur J Heart Fail 2018;20:1690-700.

149. Núñez J, Palau P, Domínguez E, et al. Early effects of empagliflozin on exercise tolerance in patients with heart failure: A pilot study. Clin Cardiol 2018;41:476-80.

150. Patorno E, Pawar A, Franklin JM, et al. Empagliflozin and the Risk of Heart Failure Hospitalization in Routine Clinical Care: A First Analysis from the Empagliflozin Comparative Effectiveness and Safety (EMPRISE) Study. Circulation 2019 [Epub ahead of print].

151. Mordi NA, Mordi IR, Singh JS, et al. Renal and Cardiovascular Effects of sodium-glucose cotransporter 2 (SGLT2) inhibition in combination with loop Diuretics in diabetic patients with Chronic Heart Failure (RECEDE-CHF): protocol for a randomised controlled double-blind cross-over trial. BMJ Open 2017;7: e018097.

152. Butler J, Hamo CE, Filippatos G, et al. The potential role and rationale for treatment of heart failure with 
sodium-glucose co-transporter 2 inhibitors. Eur J Heart Fail 2017;19:1390-400.

153. Neal B, Perkovic V, de Zeeuw D, et al. Rationale, design, and baseline characteristics of the Canagliflozin Cardiovascular Assessment Study (CANVAS) - a randomized placebo-controlled trial. Am Heart J 2013;166:217-23.e11.

154. Neal B, Perkovic V, Matthews DR, et al. Rationale, design and baseline characteristics of the CANagliflozin cardioVascular Assessment Study-Renal (CANVAS-R): A randomized, placebo-controlled trial. Diabetes Obes Metab 2017;19:387-93.

155. Neal B, Perkovic V, Mahaffey KW, et al. Optimizing the analysis strategy for the CANVAS Program: A prespecified plan for the integrated analyses of the CANVAS and CANVAS-R trials. Diabetes Obes Metab 2017;19:926-35.

156. Neal B, Perkovic V, Mahaffey KW, et al. Canagliflozin and Cardiovascular and Renal Events in Type 2 Diabetes. N Engl J Med 2017;377:644-57.

157. Rådholm K, Figtree G, Perkovic V, et al. Canagliflozin and Heart Failure in Type 2 Diabetes Mellitus. Circulation 2018;138:458-68.

158. Figtree GA, Rådholm K, Barrett TD, et al. Effects of Canagliflozin on Heart Failure Outcomes Associated with Preserved and Reduced Ejection Fraction in Type 2 Diabetes: Results from the CANVAS Program. Circulation 2019 [Epub ahead of print].

159. Perkovic V, de Zeeuw D, Mahaffey KW, et al. Canagliflozin and renal outcomes in type 2 diabetes: results from the CANVAS Program randomised clinical trials. Lancet Diabetes Endocrinol 2018;6:691-704.

160. Neuen BL, Ohkuma T, Neal B, et al. Cardiovascular and Renal Outcomes With Canagliflozin According to Baseline Kidney Function. Circulation 2018;138:1537-50.

161. Perkovic V, Jardine MJ, Neal B, et al. Canagliflozin and Renal Outcomes in Type 2 Diabetes and Nephropathy. N Engl J Med 2019 [Epub ahead of print].

162. Ryan PB, Buse JB, Schuemie MJ, et al. Comparative effectiveness of canagliflozin, SGLT2 inhibitors and non-SGLT2 inhibitors on the risk of hospitalization for heart failure and amputation in patients with type 2 diabetes mellitus: A real-world meta-analysis of 4 observational databases (OBSERVE-4D). Diabetes Obes Metab 2018;20:2585-97.

163. Patorno E, Goldfine AB, Schneeweiss S, et al. Cardiovascular outcomes associated with canagliflozin versus other non-gliflozin antidiabetic drugs: population based cohort study. BMJ 2018;360:k119.

164. Matsutani D, Sakamoto M, Kayama Y, et al. Effect of canagliflozin on left ventricular diastolic function in patients with type 2 diabetes. Cardiovasc Diabetol 2018;17:73.

165. Tanaka A, Inoue T, Kitakaze M, et al. Rationale and design of a randomized trial to test the safety and non-inferiority of canagliflozin in patients with diabetes with chronic heart failure: the CANDLE trial. Cardiovasc Diabetol 2016;15:57.

166. Wiviott SD, Raz I, Bonaca MP, et al. Dapagliflozin and Cardiovascular Outcomes in Type 2 Diabetes. N Engl J Med 2019;380:347-57.

167. Furtado RHM, Bonaca MP, Raz I, et al. Dapagliflozin and Cardiovascular Outcomes in Patients with Type 2 Diabetes and Prior Myocardial Infarction: A Sub-analy- sis From DECLARE TIMI-58 Trial. Circulation 2019 [Epub ahead of print].

168. Kato ET, Silverman MG, Mosenzon O, et al. Effect of Dapagliflozin on Heart Failure and Mortality in Type 2 Diabetes Mellitus. Circulation 2019 [Epub ahead of print].

169. Norhammar A, Bodegård J, Nyström T, et al. Dapagliflozin and cardiovascular mortality and disease outcomes in a population with type 2 diabetes similar to that of the DECLARE-TIMI 58 trial: A nationwide observational study. Diabetes Obes Metab 2019;21:1136-45.

170. Persson F, Nyström T, Jørgensen ME, et al. Dapagliflozin is associated with lower risk of cardiovascular events and all-cause mortality in people with type 2 diabetes (CVD-REAL Nordic) when compared with dipeptidyl peptidase-4 inhibitor therapy: A multinational observational study. Diabetes Obes Metab 2018;20:344-51.

171. Soga F, Tanaka H, Tatsumi K, et al. Impact of dapagliflozin on left ventricular diastolic function of patients with type 2 diabetic mellitus with chronic heart failure. Cardiovasc Diabetol 2018;17:132.

172. Yoshihara F, Imazu M, Hamasaki T, et al. An Exploratory Study of Dapagliflozin for the Attenuation of Albuminuria in Patients with Heart Failure and Type 2 Diabetes Mellitus (DAPPER). Cardiovasc Drugs Ther 2018;32:183-90.

173. McMurray JJV, DeMets DL, Inzucchi SE, et al. A trial to evaluate the effect of the sodium-glucose co-transporter 2 inhibitor dapagliflozin on morbidity and mortality in patients with heart failure and reduced left ventricular ejection fraction (DAPA-HF). Eur J Heart Fail 2019 [Epub ahead of print].

174. Cannon CP, McGuire DK, Pratley R, et al. Design and baseline characteristics of the Valuation of ERTugliflozin effIcacy and Safety CardioVascular outcomes trial (VERTIS-CV). Am Heart J 2018;206:11-23.

175. Kosiborod M, Cavender MA, Fu AZ, et al. Lower Risk of Heart Failure and Death in Patients Initiated on Sodium-Glucose Cotransporter-2 Inhibitors Versus Other Glucose-Lowering Drugs: The CVD-REAL Study (Comparative Effectiveness of Cardiovascular Outcomes in New Users of Sodium-Glucose Cotransporter-2 Inhibitors). Circulation 2017;136:249-59.

176. Kosiborod M, Lam CSP, Kohsaka S, et al. Cardiovascular Events Associated With SGLT-2 Inhibitors Versus Other Glucose-Lowering Drugs: The CVD-REAL 2 Study. J Am Coll Cardiol 2018;71:2628-39.

177. Coats AJS, Seferović PM. News from the American Heart Association: more on sodium-glucose co-transporter 2 inhibitors, diabetes and heart failure. Eur J Heart Fail 2019;21:261-3.

178. Verma S, McMurray JJV. The Serendipitous Story of SGLT2 Inhibitors in Heart Failure: New Insights from DECLARE-TIMI 58. Circulation 2019 [Epub ahead of print].

179. Zelniker TA, Wiviott SD, Raz I, et al. SGLT2 inhibitors for primary and secondary prevention of cardiovascular and renal outcomes in type 2 diabetes: a systematic review and meta-analysis of cardiovascular outcome trials. Lancet 2019;393:31-9. 